\title{
High resolution operational modal analysis of Sant'Agata del Mugello in light of its building history.
}

\author{
Arnaud Montabert ${ }^{* 1,3,4}$, Diego E. Mercerat ${ }^{2}$, Julien Clément $^{3}$, Philippe Langlaude $^{2}$, \\ Hélène Lyon-Caen ${ }^{1}$, and Maria Lancieri ${ }^{4}$
}

${ }^{1}$ Laboratoire de Geologie, CNRS U.M.R.8538, Ecole Normale Superieure, PSL, 24 Rue Lhomond, 75005, Paris, France

${ }^{2}$ CEREMA Méditerranée, project team MOUVGS, 500 route des Lucioles, 06903 Sophia Antipolis, France

${ }^{3}$ Institut de Radioprotection et de Sûreté Nucléaire (IRSN), PSN-EXP/SES/LMAPS, 31, avenue de la Division Leclerc, BP 17, 92262 Fontenay-aux-Roses, CEDEX, France

${ }^{4}$ Institut de Radioprotection et de Sûreté Nucléaire (IRSN), PSE-ENV/SCAN/BERSSIN, 31, avenue de la Division Leclerc, BP 17, 92262 Fontenay-aux-Roses, CEDEX, France

\begin{abstract}
The building history of a cultural heritage building and the after-effects induced by extreme loads such as earthquakes have a durable impact on its modal parameters. This article aims to discuss the peculiarities of some modal parameters extracted from ambient vibration measurements in light of the complex history of Sant'Agata del Mugello. The Romanesque church located in the Mugello basin (Tuscany, Italy) suffered from many earthquakes, at least from 1542. In this context, we carried out two dense ambient vibration campaigns in March and June 2019. We extracted each mode's natural frequency, mode shape, and damping using the Enhanced Frequency Domain Decomposition. We identified ten modes. Some modes highlight structural singularities related to the building history of the church: rocking of the base of the bell tower; phase opposition between the bell tower and the nave; bending of the walls of the nave. Since the instrumentation benefited from a vast number of recording positions (83), we tested the impact of the sensor placement strategy on the resolution of the identified modal parameters in the specific case of Sant'Agata del Mugello. The resolution of the higher-order modes decreases strongly in case of degraded sensor placement strategy impacting the dynamic analysis of the church.
\end{abstract}

Keywords - Operational Modal Analysis, Enhanced Frequency Domain Decomposition, natural frequency, mode shape, damping ratio, medieval church, masonry, sensor placement.

\section{Highlights}

- We performed two in situ campaigns to estimate the modal parameters of the Sant'Agata del Mugello church.

- We highlight the impact of the building history and after-effects of historical earthquakes on modal parameters.

- We highlight the impact of the sensor placement strategy on modal parameters.

${ }^{*}$ Corresponding author presently working at: Université Paris-Saclay, CentraleSupélec, ENS Paris-Saclay, CNRS, Laboratoire de Mécanique Paris-Saclay, 91190, Gif-sur-Yvette, France. E-mail adresses : montabert@geologie.ens.fr, arnaud.montabert@ens-paris-saclay.fr

${ }^{0}$ Received 23 July 2021; Received in revised form 27 October 2021; Accepted 12 December 2021 for publication in Engineering Structures 


\section{Introduction}

Over the last decades, ambient vibration tests have been successfully used to extract modal parameters of buildings in a non-invasive way. These parameters are generally used in the context of preservation of the building through Structural Health Monitoring (SHM) or the establishment of representative models for simulating the expected response.

Ambient vibration measurements performed before and after a seismic event showed that the related damage had an impact on the modal parameters: drop in frequency, increase in modal damping, modification of mode shape (e.g. [1]). The modal parameters may also be impacted by the peculiarities of the structure acquired during its history: asynchronous construction, reconstruction operation, repairs (e.g. [2]).

Understanding how asynchronous constructions influence the modal parameters is crucial when dealing with the numerical model of ancient buildings, especially when located in seismic areas. For this reason, in this paper, we investigate the sensitivity of empirical methods characterizing the modal parameters to construction heterogeneities and the impact of the sensor setups geometry and density.

The church of Sant'Agata del Mugello was chosen as a case study since its building history has been exhaustively documented in a previous paper [3]. Indeed, a cross-disciplinary approach combining a stratigraphic analysis of the church's walls with information extracted from historical documents revealed the asynchronous construction of the church and numerous repairs associated with historical earthquakes. Thirteen building phases and 80 repair units were identified. The questions arising are what are the modal parameters of this Cultural Heritage building and what are the links with the building phases?

Non-invasive experimental techniques must be used. Among them, Operational Modal Analysis (OMA) guarantees conservation and integrity of the building [4] since no excitation equipment is needed and the tests only consist in measuring the response of the building to environmental excitations [5].

OMA is indeed widely used to study conventional buildings (e.g. [6, 7]). Its application to cultural heritage buildings increased in the last twenty years. A non-exhaustive, though quite complete, list of historic buildings wellinstrumented in the last decades is summarized Table 1. Most of these studies are focused on a specific component of a building (dome, vault, arch) or on slender structures like towers, chimneys, and minarets (almost $65 \%$ of the instrumented buildings). Only a few numbers of entire historical buildings have been investigated (church, cathedral, basilica, pagoda). There are two main reasons for this: the complexity of the behavior of the ancient masonry and the complexity related to the building history. The low-response level of masonry to ambient excitation highlights its complex behavior. Many factors increase this complexity: the building geometry inducing a mixture between flexural and torsional modes [8], the presence of many local modes interspersed among the global modes, the nonlinear behavior of the masonry even for low stress levels [9]. Asynchronous construction, repairs and retrofitting interventions change the stiffness properties of the building and then the modal parameters [10, 11].

Among OMA techniques, frequency and time domain methods are widely used to extract modal parameters. For highly uncertain problems, the two approaches are used to generate consistent results (e.g. [12, 13]). For fairly regular and simple buildings, the frequency domain method alone is enough to identify the structure's mechanical properties [14, 15, 16]. In the case of Sant'Agata del Mugello, the Enhanced Frequency Domain Decomposition (EFDD) is used to extract modal parameters (the natural frequency, the damping ratio, and the mode shape). This method has the advantage of quickly identifying natural frequencies.

Frequency and spatial resolution play a significant role in overcoming the difficulties above. The frequency resolution is controlled by the sampling rate and the measurement duration. It is generally admitted that the measurement duration should be at least 2000 times the natural period of interest [17]. The spatial resolution mostly depends on the sensor placement and their number. Only a reduced number of points are generally recorded after identifying the optimal sensor placement. By contrast, identifying local behaviors would require an accurate spatial resolution for a building with a rich and complex history. In the specific case of Sant'Agata del Mugello, the placement of the sensors is a compromise between the use of a minimum of degrees of freedom and a sensor network dense enough to identify peculiarities of modal parameters induced by the building's history.

To deal with this challenge, two ambient vibration measurement campaigns were conducted at the scale of the entire building of the Sant'Agata del Mugello church in March and June 2019. Sant'Agata del Mugello was densely instrumented, allowing the measurement of 249 degrees of freedom (Table 1). Given the relative small size of the church, this large number of measurements is one of the specificity of this study. In this paper, the resolution of the identified modal parameters in relation to the instrumentation strategy and the building's history is discussed 
in the specific case of Sant'Agata del Mugello taking advantage of such dense sensor distribution. Because it is not always possible to install such a dense sensor network inside a building and because it is an opportunity to quantify the impact of our technical choices, analyses are performed using fewer measurement points in order to observe the impact on the identification of the mode shapes.

Slender structures

Complex structures

\begin{tabular}{|c|c|c|c|c|c|}
\hline Building name & DoFs & Type & Building name & DoFs & Type \\
\hline Mogadouro Clock tower [18] & 54 & tower & $\begin{array}{l}\text { St.'Agata del Mugello [19], this } \\
\text { study }\end{array}$ & 249 & church \\
\hline Hagia Sophia's bell tower [5] & 48 & tower & Cathedral of Santiago [20] & 234 & cathedral \\
\hline St. Silvestro Belfry [21] & 40 & tower & Notre Dame de la Gorge [10] & 93 & church \\
\hline Vistula Mounting Fortress'tower [22] & 36 & tower & St. Maria Di Collemaggio basilica [23] & 78 & basilica \\
\hline Palazzo Margherita's tower [24] & 30 & tower & St. Mary's basilica [8] & 57 & basilica \\
\hline Annunziata church [25] & 26 & tower & San Francesco church [26] & 47 & church \\
\hline Tokoname's chimney [27] & 26 & chimney & Jagannath Temple [28] & 44 & pagoda \\
\hline Announziata's bell tower [29], [30] & 24 & tower & St. Torcato church [16] & 35 & church \\
\hline Monza Cathedral's bell tower [31] & 20 & tower & St. Maria Assunta Cathedral [32] & 31 & cathedral \\
\hline Porto's chimney [33] & 20 & chimney & church of Monastery of Jerónimos [18] & 30 & church \\
\hline Torre delle Ore [34] & 18 & tower & Palazzo Margherita [35] & 30 & palace \\
\hline Ancient water towers $[36]$ & 18 & tower & Yechheswor temple [37] & 28 & pagoda \\
\hline $\begin{array}{l}\text { The Bell tower of S. Giovenale's cathe- } \\
\text { dral [38] }\end{array}$ & 18 & tower & Salan Ganesh temple [37] & 26 & pagoda \\
\hline The bell tower of S. lucias's church [39] & 16 & tower & Santa Maria Maddalen [40] & 23 & church \\
\hline Manjaq Al-Yusufi minaret [41] & 15 & minaret & Visitazione church [42] & 22 & church \\
\hline St. Giorgio church [43] & 13 & tower & San Giuliano [42] & 22 & church \\
\hline San Frediano bell tower $[44]$ & 12 & tower & Nyatopol temple $[37]$ & 22 & pagoda \\
\hline St. Maria Del Carmine's bell tower [45] & 12 & tower & San Pedro Apostol church [46] & 20 & church \\
\hline Vilnius Arch-Cathedral Belfry [47] & 12 & tower & San Juan Bautista church [46] & 20 & church \\
\hline The Trajan column [48] & 11 & Column & Palazzo Pica Alfieri [49] & 18 & palace \\
\hline St. Maria del Carrobiolo [14] & 10 & tower & St. Maria delle Grazie [38] & 18 & church \\
\hline $\begin{array}{l}\text { The minaret of Hagia Sophia ( } 1,2 \text { and } \\
\text { 3), Yeni Cami, Akbiyık, Mihrimah, } \\
\text { Rüstem Pas,a, Süleym (2) and Şehzade, } \\
{[50]}\end{array}$ & 9 & minaret & Madonnina della Neve [38] & 18 & church \\
\hline Crisanti-Diodoro's chimney [51] & 9 & chimney & Chiesa Collegiata's bell tower [15] & 15 & church \\
\hline Capua's Dome bell tower [52] & 8 & tower & Armenian church [53] & 14 & church \\
\hline $\begin{array}{l}\text { Matildea tower, Pomposa Abbey } \\
\text { and San Giorgio Cathedral and San } \\
\text { Benedetto church Belfry [54] }\end{array}$ & 8 & tower & Regina Montis Regalis basilica [55] & 12 & basilica \\
\hline St. Justa and Rufina's bell tower [56] & 8 & tower & Mexico City Cathedral [57] & 8 & cathedral \\
\hline The minaret of Prince Shaykhou [58] & 8 & minaret & Radha Krishna [59] & 6 & pagoda \\
\hline The tower of Soncino [60], [61] & 7 & tower & St. Maria in Aracoeli church [62] & 4 & church \\
\hline Torre Grossa [63] & 7 & tower & & & \\
\hline Duomo di Milano's main spire. [64] & 6 & tower & & & \\
\hline $\begin{array}{l}\text { Nuestra Señora Candelaria de la Viña } \\
\text { [65] }\end{array}$ & 6 & tower & & & \\
\hline The St. Andrea bell tower [66] & 6 & tower & & & \\
\hline Howa's and Iwata's chimney [67] & 6 & chimney & & & \\
\hline Aversa's Dome bell tower [52] & 4 & tower & & & \\
\hline Chiesa della Maddalena's bell tower [68] & 4 & tower & & & \\
\hline The Febonio tower [69] & 3 & tower & & & \\
\hline The San Maggiore cathedral [70] & 2 & tower & & & \\
\hline Nuestra Sra. de la Misericordia's bell & 2 & tower & & & \\
\hline
\end{tabular}

tower [71]

Table 1: Catalog of well instrumented cultural heritage building. The studies on slender structures are summarized on the left whereas those on more complex whole structures are summarized in the right column. DoFs indicate the number of degree of freedom measured. 
The paper is structured as follows. The building and seismic history of the church are first summarized. The main concepts of EFDD and the code used are then briefly exposed. The two instrumentation campaigns are presented, focusing on technical challenges encountered in-situ. The results of the two high-resolution Operational Modal Analyses are detailed and discussed in light of the building history of the church. In the last part, placement strategies are tested to discuss their impact on the extraction of modal parameters in the specific case of Sant'Agata del Mugello.

\section{The church of Sant'Agata del Mugello}

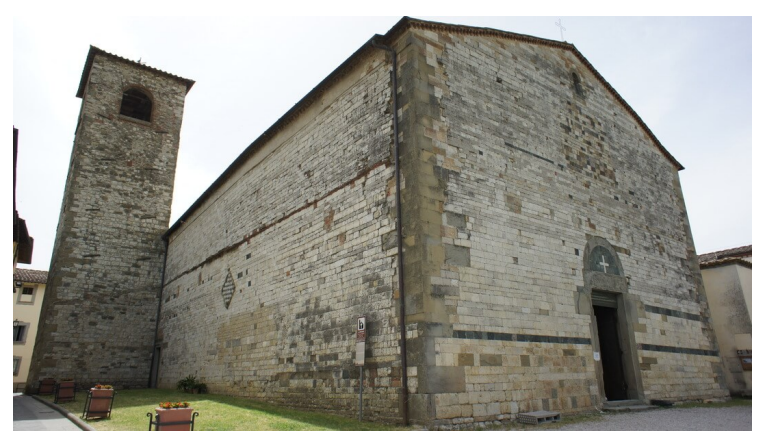

Figure 1: External view of Sant'Agata del Mugello (Di Mongolo1984 - Opera propria, CC BY-SA 4.0.

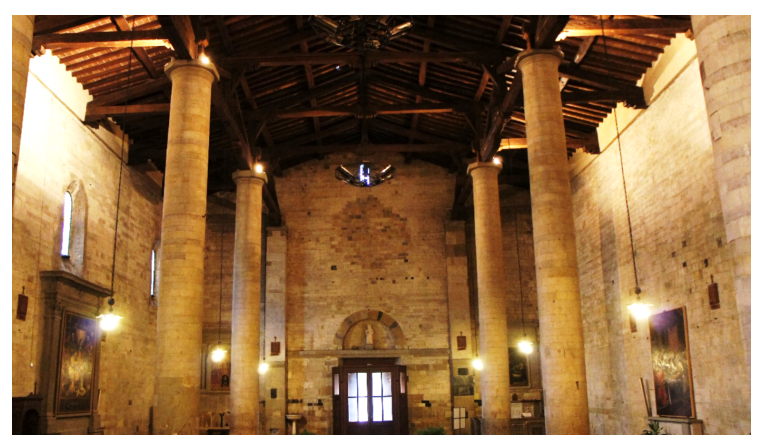

Figure 2: Internal view of Sant'Agata del Mugello (Photos credits: Maria Lancieri).

Sant'Agata del Mugello is a Romanesque church (Fig. ??env=Figs.]fig:minipage1, Fig. 3) located in the Mugello basin $30 \mathrm{~km}$ North of the city of Florence (Tuscany, Italy). As part of the Northern Apennines, the Mugello sector is characterized by a rather moderate seismicity [72]. Mugello is an intramontane basin bordered by two large antithetic normal fault systems where earthquakes have been reported at least since the middle of the 16th century. The largest historical earthquakes occurred in 1542 (estimated macroseismic moment magnitude Mmw $=6.0$ ) and in 1919 (estimated $\mathrm{Mmw}=6.4$ ), located about 5 and $30 \mathrm{~km}$ from the church, respectively [73]. The 1542 seismic event deeply affected the building history of the church, as described below. Seismic crises characterized by shallow earthquakes were recorded in 2008 and 2009 [74] and more recently in 2019, which justifies the analysis of the seismic vulnerability of the church.

At present, the building is composed of several parts: the nave, the central apse, two lateral chapels, and the bell tower (Fig. 3). A cloister was built near the southern facade of the church. Since the two buildings are in contact only in the northeast corner of the nave, this study does not consider the cloister.

The rectangular nave $(15.7 \mathrm{~m} \times 29.3 \mathrm{~m}$, Fig. 3) draws its singularity by its unique wooden frame (Fig. 2); its walls are about $0.80 \mathrm{~m}$ thick. The central apse $(15.7 \mathrm{~m} \times 29.3 \mathrm{~m}$, Fig. 3) and the two squared lateral chapels $(4.4 \mathrm{~m} \times 4.4 \mathrm{~m}$ and $4.5 \mathrm{~m} \times 4.5 \mathrm{~m}$ for the North and South chapel, respectively) are overhung by a vault system; their wall thicknesses range from $0.40 \mathrm{~m}$ to $0.70 \mathrm{~m}$. The bell tower (Fig. 1) is $21 \mathrm{~m}$ high. Its plan is almost square $(6.3 \mathrm{~m} \times 6.0 \mathrm{~m})$ and the masonry walls are $1.10 \mathrm{~m}$ thick. 


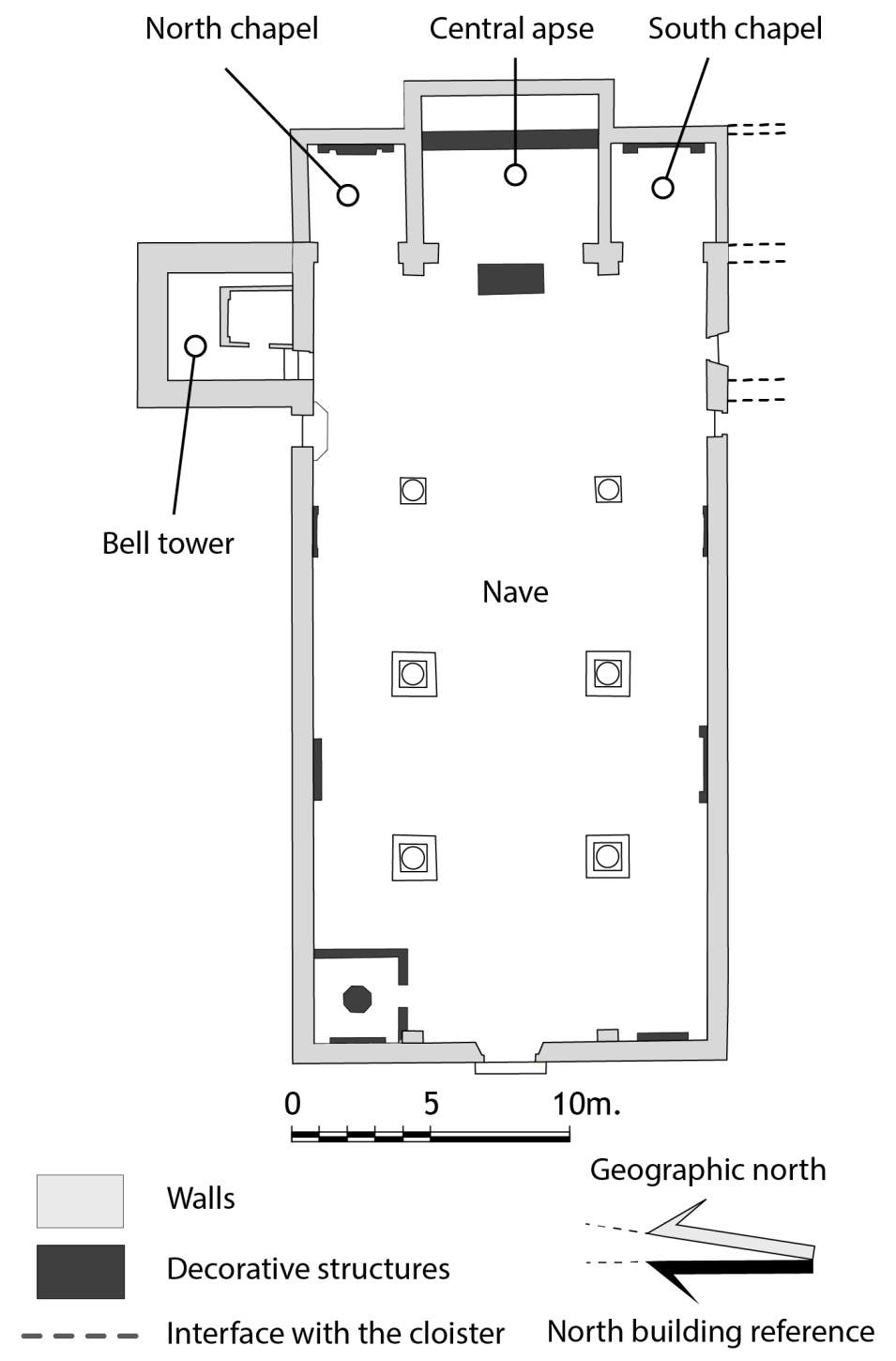

Figure 3: Plan of the Sant'Agata del Mugello church (adapted from [3]).

An in-depth study of the church combining data found in archives, stratigraphic analysis and an engineering diagnosis highlight an asynchronous architectural evolution in terms of geometry and material used (13 building phases have been identified) [75,3].

The first signs of a church date from before the 10th century. In the 15th century, the building was only composed of the nave and the central apse. During this century, the two side chapels were successively added, followed by the bell tower in a final stage. The earthquake of June 6, 1542 (estimated macroseismic Mmw = 6.0, [73]) induced plenty of damage: the upper part of the bell tower collapsed and cracks opened in the west and east wall of the bell tower. Only the south wall of the bell tower was rebuilt to its original height, changing the bell tower to a vertical L-shape tower. The outer side of the facade, the north wall, and the south wall of the nave are still tilting. The two lateral chapels collapsed and have been rebuilt using a different building technique. The earthquake of September 8 , 1611 (estimated macroseismic Mmw = 5.1) induced cracks in the L-shape bell tower and weakened the upper part leading the bell tower to its current shape after an in-depth reconstruction. The 1919 earthquake (Mmw 6.4) did not induce any damage. The arising questions are if and how this rich complex building history affects the building modal parameter to be used for numerical simulation. For this reason, we applied the EFDD technique introduced below. 


\section{Methods}

\subsection{Theoretical background of Enhanced Frequency Domain Decomposition}

The Enhanced Frequency Domain Decomposition (EFDD) technique [76] is used to extract natural frequencies, mode shapes, and damping ratios. The input motion $x(t)$ is considered as unknown, and only the output velocity $y(t)$ is measured (Output-Only method). The relationship between the input $x(t)$ and the output $y(t)$ can be written in the following form $[77,78,79]$ :

$$
\left[G_{y y}(\omega)\right]=[H(\omega)]^{*}\left[G_{x x}(\omega)\right][H(\omega)]^{H}
$$

where:

- * and ${ }^{H}$ denote complex conjugate and the complex conjugate transpose;

- $\left[G_{y y}(\omega)\right]$ is the $r \times r$ output power spectral density (PSD) matrix, $\mathrm{r}$ is the number of outputs (the number of recording channels);

- $\left[G_{x x}(\omega)\right]$ is the $m \times m$ input power spectral density (PSD) matrix, $m$ is the number of inputs;

- $[H(\omega)]$ is the $r \times m$ Frequency Response Function (FRF) matrix;

The Power Spectral Density matrices $\left[G_{y y}(\omega)\right]$, i.e. the Fourier Transform of the correlation matrices are first estimated using the Welch method [80], i.e. Fourier Transforms of overlapping regular windows of the crosscorrelation are averaged. The singular value decomposition of these matrices is then performed at discrete known frequencies $\omega_{i}$ as follows:

$$
\left[G_{y y}\left(j \omega_{i}\right)\right]=\left[\Phi_{i}\right]^{*}\left[S_{i}\right]\left[\Phi_{i}\right]^{H}
$$

where $\left[S_{i}\right]$ is a diagonal matrix holding the scalar singular values and $\left[\Phi_{i}\right]$ is a unitary matrix whose first column corresponds to the associated singular vector. The first singular value exhibits a peak (Fig. 4-a) that defines the natural frequency of the mode [79] while the associated singular vector defines its shape. At this step, the simultaneity of the recordings is particularly important to identify the mode shape since it allows to keep the information on the relative phase between sensors.

Enhanced Frequency Domain Decomposition [79] provides a better mode decomposition than the classical FDD technique. By comparing the aforementioned selected mode shape with those associated to the surrounding frequency values even in the second singular value, SV2 (Fig. 4-a), the Single Degree Of Freedom (SDOF) density function can be selected in the singular values using the Modal Assurance Criterion (MAC), computed as follows:

$$
M A C=\frac{\left|\left\{\phi_{1}\right\}^{H}\left\{\phi_{2}\right\}\right|^{2}}{\left|\left\{\phi_{1}\right\}^{H}\left\{\phi_{1}\right\}\right|\left|\left\{\phi_{2}\right\}^{H}\left\{\phi_{2}\right\}\right|}
$$

where two mode shapes $\left\{\phi_{1}\right\}$ and $\left\{\phi_{2}\right\}$ are compared. Singular values belonging to the same SDOF density function are selected for a MAC value above a certain threshold (here defined as $80 \%$ ).

The identified SDOF density function that fits data represents the Transfer Function of the SDOF system (Fig. 4-b), characterized by its frequency peak. Its Inverse Fourier Transform (IFT) provides the Impulse Response Function (IRF) of the mode [76] and the damping value is then computed using the random decrement method (Fig. 4-c) [81]. 

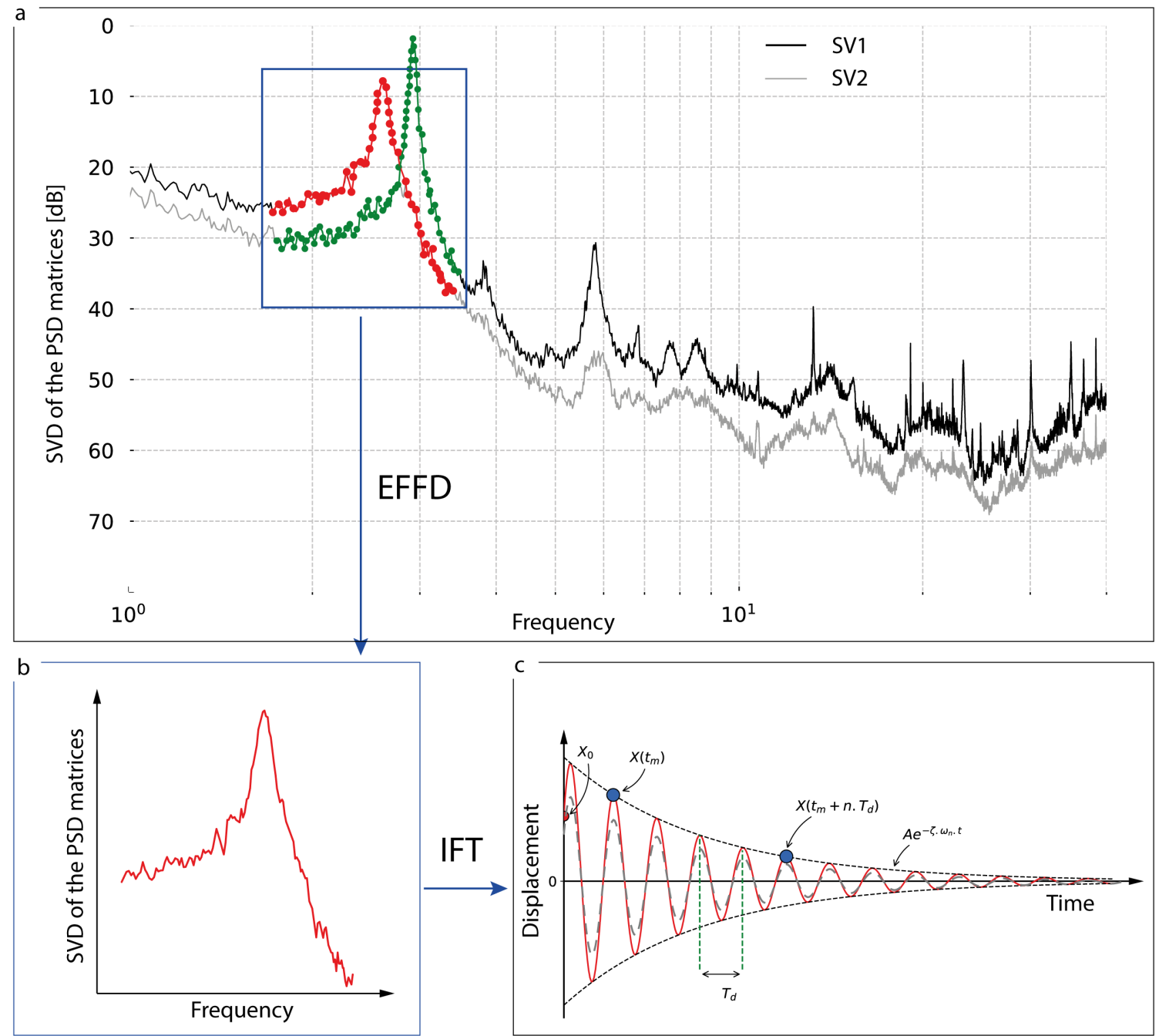

Figure 4: (a) Evolution of the first and second singular values (SV1 and SV2) in the case of the bell tower of Sant'Agata del Mugello. Red and green dots correspond to singular values for which the MAC value between the mode shape associated with the frequency peak $(2.61 \mathrm{~Hz}$ and $2.92 \mathrm{~Hz})$ and the mode shapes of the surrounding frequencies is over $80 \%$. (b) SDOF density functions of the first bending mode were extracted using the MAC. (c) IFT of the identified SDOF density function provides the Impulse Response Function of the mode.

The Mode Complexity Factor (MCF) [82] can be used to control the complexity of each identified mode shape. It is defined as:

$$
M C F=1-\frac{\left(S_{x x}-S_{y y}\right)^{2}+4 S_{x y}^{2}}{\left(S_{x x}+S_{y y}\right)^{2}} e l e q:: m c f
$$

Where $S_{x x}=\operatorname{Re}\left(\{\phi\}^{T} \operatorname{Re}(\{\phi\}), S_{y y}=\operatorname{Im}(\{\phi\})^{T} \operatorname{Im}(\{\phi\}), S_{x y}=\operatorname{Re}(\{\phi\})^{T} \operatorname{Im}(\{\phi\})\right.$ and $\{\phi\}$ the mode shape associated with the frequency peak. This value evolves between 0 (Real Mode) and 1 (Imaginary Mode).

The MACity Matlab code proposed by Michel [6] implementing the approach mentioned above was used. The code allows computing the PSD matrices of simultaneous recordings using Welch's method with a Hanning windowing and a $50 \%$ overlapping. Windows with a number of points in the power of 2 were used to optimize the computation of Fast Fourier Transforms. 8192 points corresponding to $40.96 \mathrm{~s}$ at $200 \mathrm{~Hz}$ were used, leading to a frequency resolution of about $0.024 \mathrm{~Hz}$. Data were bandpass filtered between 1 and $30 \mathrm{~Hz}$ using a 4th order Butterworth filter. The spatial resolution of our measurements did not allow us to identify modes above $30 \mathrm{~Hz}$. Singular values that belong to the SDOF density function for a MAC threshold greater than $80 \%$ were selected. We implement the MCF in the MACity code. 


\section{Experimental campaigns}

Two experimental campaigns were completed in March and June 2019. They consisted of measuring the church's response to ambient vibrations at selected points. To identify sensor placement, we chose accessible points first. A preliminary model was then used to select those whose mode shapes of searched modes reached the largest amplitudes. Because of the complex building history of the church induced by the asynchronous construction of the bell tower and the repairs after the 1542 and 1611 historical earthquakes, a dense network was designed. We used two types of tri-axial velocimeters to record the background noise velocity containing vibrations of the church: 6 CMG40-T-1 (with a flat response between $0.2 \mathrm{~Hz}$ to $50 \mathrm{~Hz}$ ) and 6 LE-3Dlite MkIII (with a flat response between $1 \mathrm{~Hz}$ to $50 \mathrm{~Hz}$ ). Data sets were recorded with a $200 \mathrm{~Hz}$ frequency rate. One Cityshark II (18 synchronized channels) 24-bit acquisition system was used to synchronize 6 CMG40-T-1 in March 2019 during the instrumentation of the bell tower. Two Cityshark II were used during the instrumentation of the nave in June 2019: one to synchronize 6 CMG40-T-1 and another to synchronize 6 LE-3Dlite MkIII. Because of the limited number of sensors, several setups were defined to recover the entire building. A setup consists of an array of instruments where the building response is simultaneously recorded. The two campaigns allowed the measurements of 83 nodes in the church. The recordings at each node were synchronized thanks to the sensor clock adjusted using UTC obtained from GPS devices. The structure response is recorded for at least $1 \mathrm{~h}$; this is consistent with an empirical rule given by Rodriguez [17] where the measurement duration is recommended to be at least 2000 times the natural period of interest, e.g. if the first modes of the church is expected around $2 \mathrm{~Hz}$, the measurement duration should be at least 17 min.

\subsection{The March 2019 campaign}

The March campaign was focused on the bell tower, the most accessible part of the church. It is composed of 5 floors, and we measured 4 vertical setups (Fig. 5). The reference sensor was located on top of the bell tower (Fig. 6-a, sensor ID 1 in Fig. 5). This provided a reference point to normalize and combine all the mode shape components. Several nodes were also added at level 0 of the church to detect potential bending at the basement.
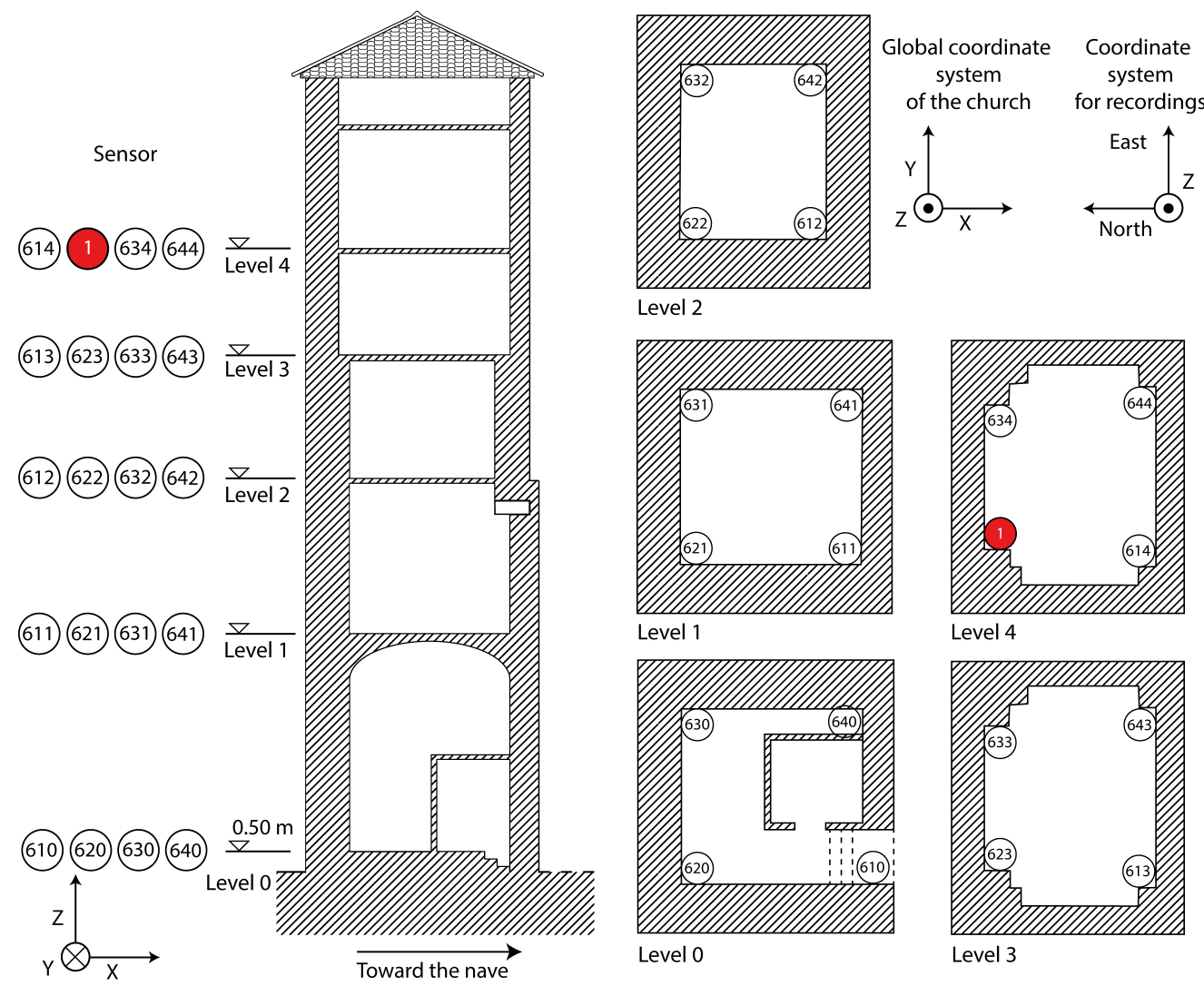

Figure 5: Location of the tri-axial sensors during the 2019 March survey in the bell tower. The reference sensor is shown in red. Numbers correspond to the ID of sensors used. The coordinate system for recordings is oriented along the North building reference shown in Fig. 3. 

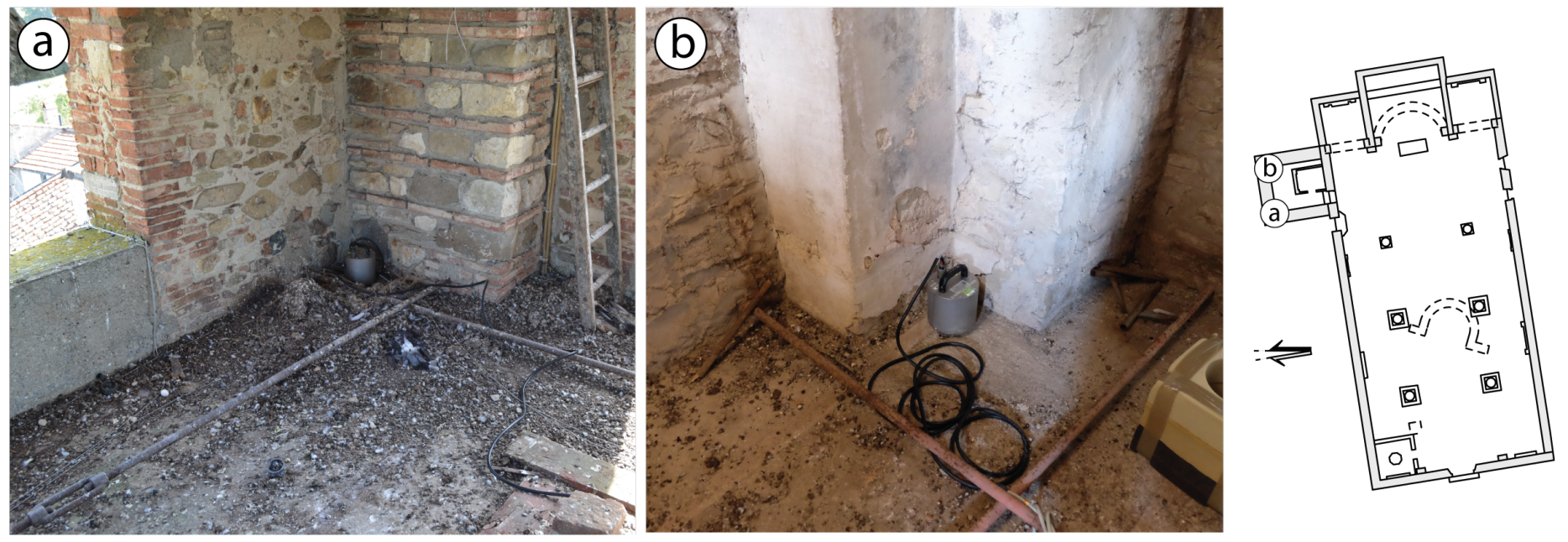

Figure 6: The tri-axial sensors (CMG40-T-1) in the bell tower during the March 2019 campaign. (a) Reference sensor installed at the top of the bell tower (node 1 in Fig. 5). (b) Sensor installed at level 1 of the bell tower (node 631 in Fig. 5 ). The location of the two sensors is depicted on a plan on the right of the figure. (Photos credits: Arnaud Montabert)

\subsection{The June 2019 campaign}

The June 2019 campaign was focused on the nave. Ambient vibrations were recorded at several levels (Fig. 7): the lower part of the building at ground level (level 0), the middle part of the building (level 1), and the top part (level 2), which is the most likely to record the largest amplitudes. As level 1 offers few possibilities to install seismometers, only 11 points were measured. This sensor strategy was validated by computing the first modes of the church by using a preliminary FE model. It was a real technical challenge to instrument level 2 since there was no direct access (no vaults system). We had to use a "spider" aerial platform (Fig. 8-a) with two operators (one operator at the top to control the platform and one operator at the bottom to ensure a second visual control). The sensors were thus installed on wooden beams as the only flat surfaces at level 2. Although wood may affect the signal, it was also impossible to stick any miniature accelerometers to the wall at his height. The sensors were thus installed as close as possible to the walls of the nave using straps (Fig. 8-b), preventing the fall of sensors. There were also strapped at the top of the columns of the central nave at a height of about $10 \mathrm{~m}$. The reference sensor was installed on the North-West beam (location ID 1 shown in Fig. 7). Sensors (CMG40-T-1) were deployed on the ground (level 0) at the foot of level 2 sensors (LE-3Dlite). Some sensors were installed in the middle part of the nave at the level of the openings in the walls, or on the tabernacles when the coupling between the latter and the walls was proven (CMG40-T-1 and LE-3Dlite at level 1). Ambient vibrations were also recorded in the bell tower since the interface between the bell tower and the nave is a sensitive area. Pounding effects are indeed expected since the bell tower was built after the nave without any obvious mechanical link. We measured only one vertical line to compare modal parameters with those obtained in March 2019. 

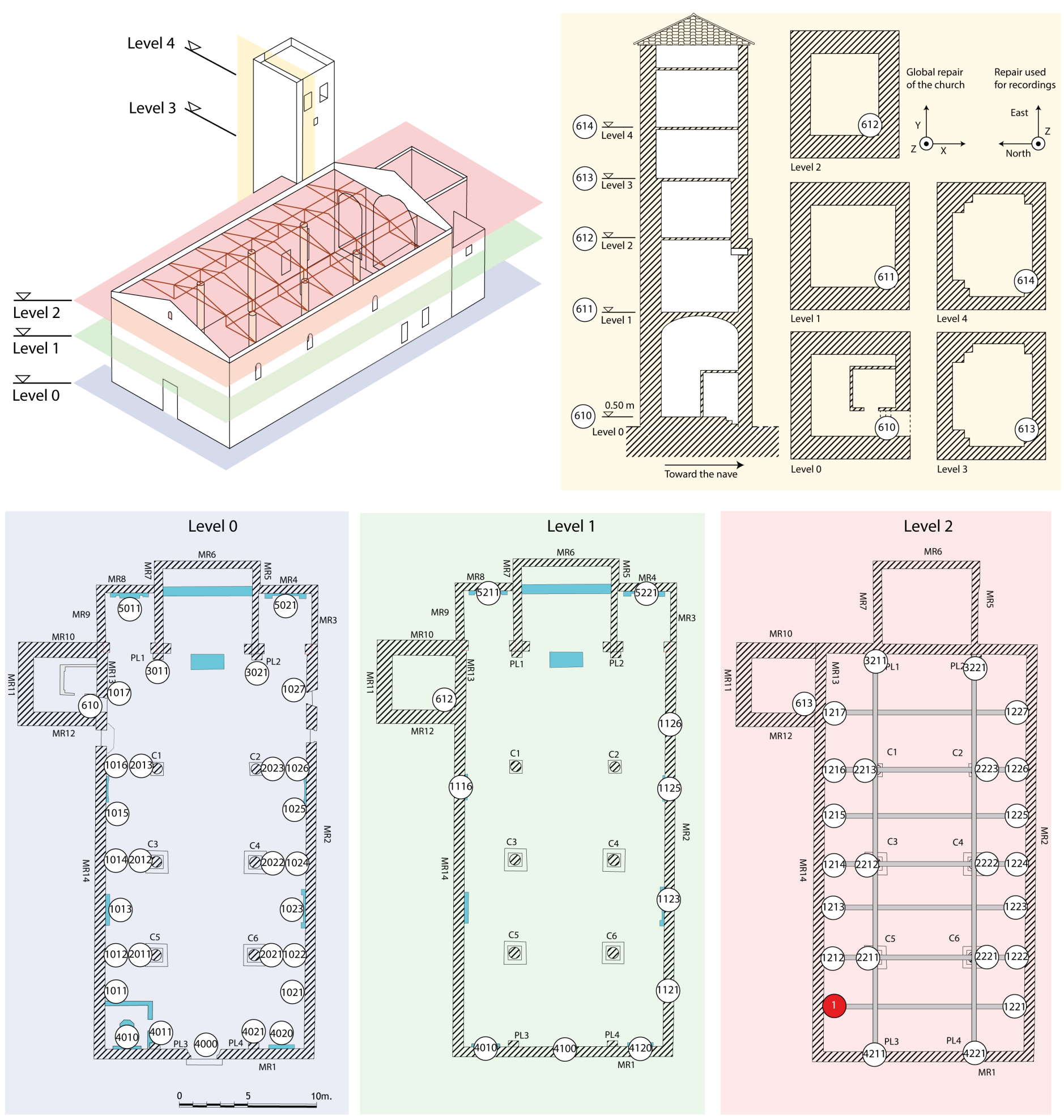

Figure 7: Location of the sensors during the June 2019 survey in the church at three levels. Level 0 : the ground floor, level 1: openings and tabernacles, level 2: wood frame of the church. 5 seismometers were also installed in the bell tower. The reference sensor is shown in red.

All parts of the church have been instrumented: the nave, the bell tower, the central apse, and the two lateral chapels. 11 setups have been designed, and the survey lasted almost 4 days. 

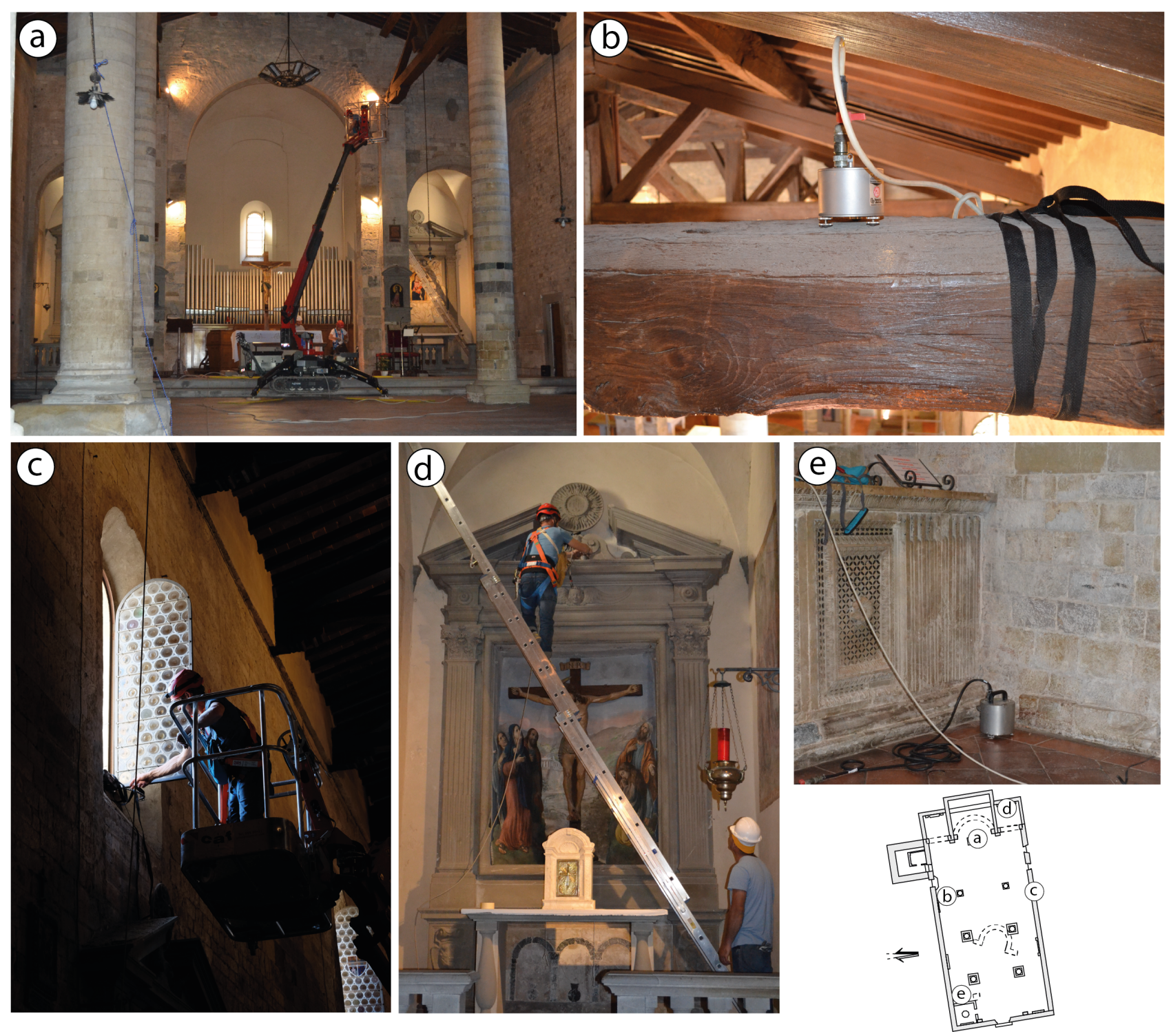

Figure 8: Location of the sensors during the June 2019 survey. (a) Use of a "spider" aerial platform to install sensors on the beams of the wooden frame with two operators. (b) LE-3Dlite MkIII strapped on a beam at level 3. (c) Installation of a sensor on one of the three windows of the church. (d) Installation of a sensor on a tabernacle in the south side chapel. (e) Installation of a sensor (CMG40-T-1) on the ground floor. We specify the location of the five seismometers in the plan of the church on the right in the Figure. Photo credits: Hélène Lyon-Caen ( $a, c)$ and Arnaud Montabert (b, d, e).

\subsection{Signal processing}

After time oversampling, recordings from the 2 Citysharks were synchronized. Records were then corrected from the instrumental response. In order to avoid amplification of the frequency content of the instrumental noise during the deconvolution process, a bandpass pre-filtering between $0.5 \mathrm{~Hz}$ and $50 \mathrm{~Hz}$ was then applied.

\section{Results of the operational modal analysis of March and June 2019}

The EFDD technique described in Fig. 4 is used to evaluate the modal parameters of the church summarized in Table 2. Fig. 9 shows the first six average singular values of the PSD matrices for the 4 setups recorded during the March 2019 campaign described in Fig. 5. Fig. 10 shows the first six average singular values of the PSD matrices for the 7 setups recorded during the June 2019 campaign described in Fig. 7. 10 peaks are identified in the first campaign (Fig. 9). 12 peaks are identified in the second one (Fig. 10). Modes 1 and 6 are observed on both surveys. 
They are noted 1-1 (respectively 6-1) and 1-2 (respectively 6-2). The associated mode shapes of the selected peaks and their SDOF density function are shown by increasing frequency in Fig. ??, respectively.

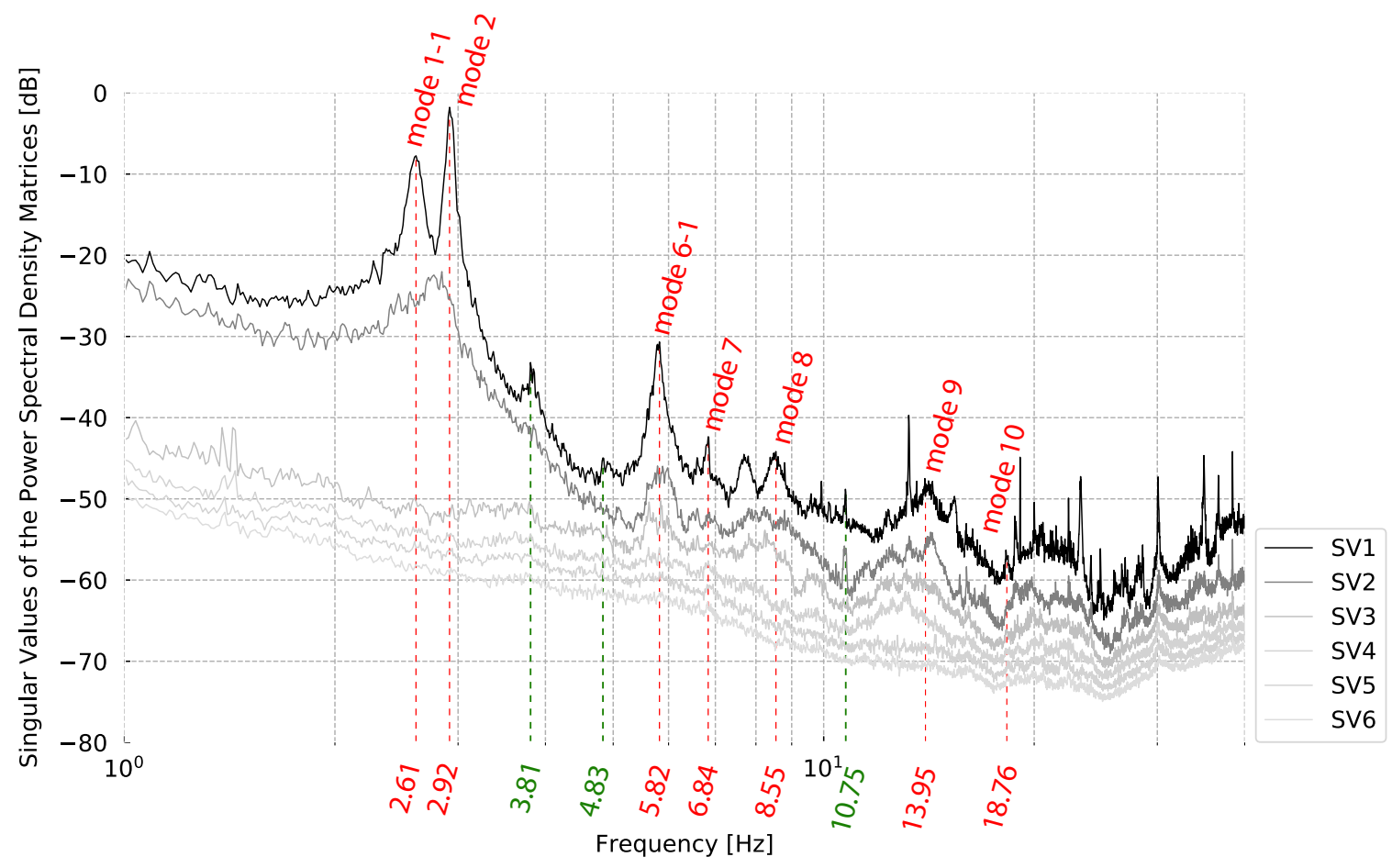

Figure 9: Evolution of the 6 first average singular values (SV1, SV2, SV3, SV4, SV5, SV6) of the Power Spectral Density matrix extracted from the 4 setups in the bell tower (March 2019 campaign) as a function of frequency. 10 peaks are identified. Red values correspond to the identified natural frequencies of the bell tower. Green values correspond to the natural frequencies of the nave that cannot be characterized since the instrumentation is focused on the bell tower.

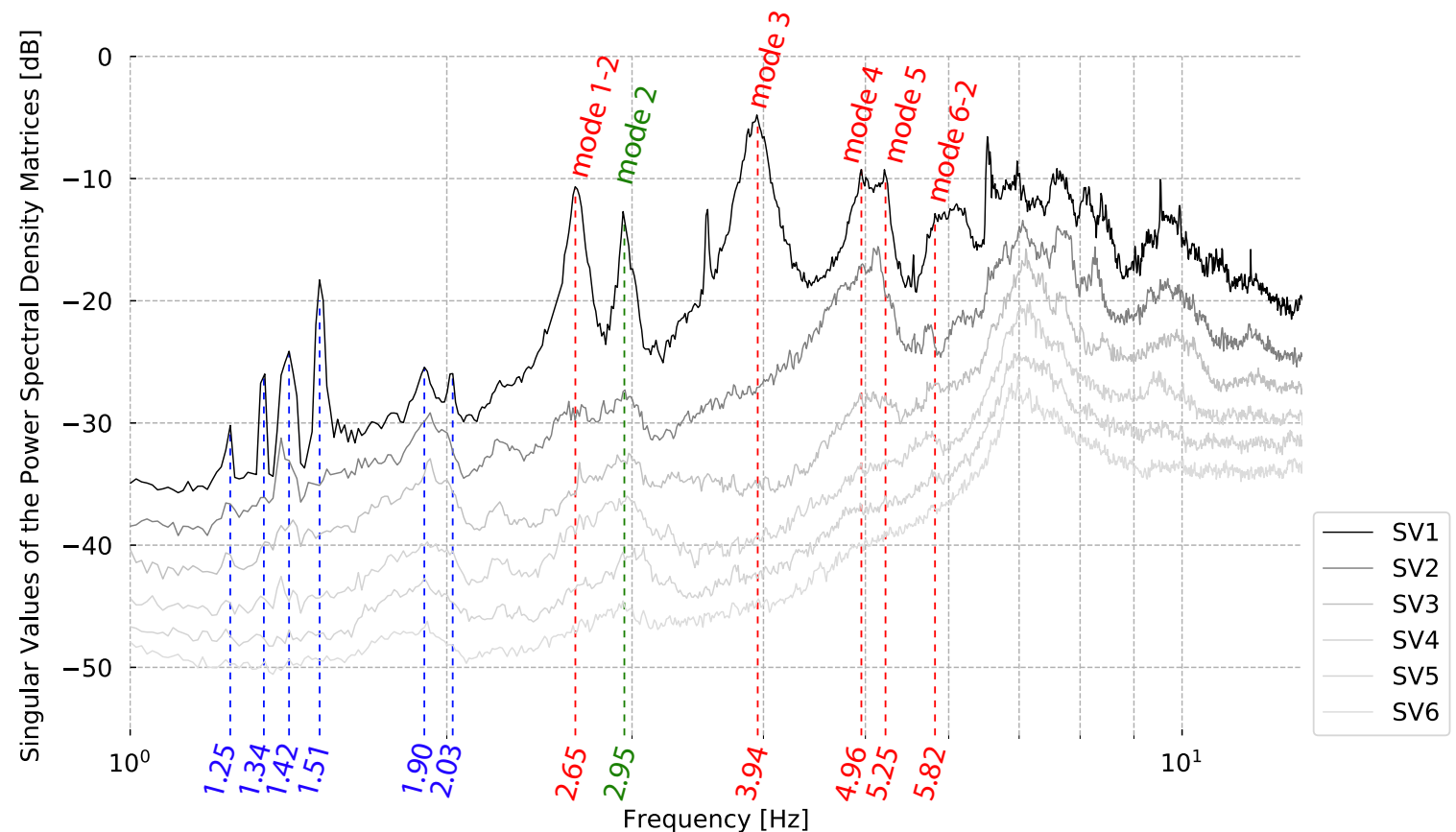

Figure 10: Evolution of the 6 first average singular values (SV1, SV2, SV3, SV4, SV5, SV6) of the Power Spectral Density matrices extracted from the 7 setups in the nave (June 2019 campaign). Red values correspond to the natural frequencies of the nave. The green value corresponds to the natural frequencies of the bell tower that cannot be characterized since the instrumentation is focused on the nave. Blue values highlight frequencies of non-structural modes, as explained in the text. 

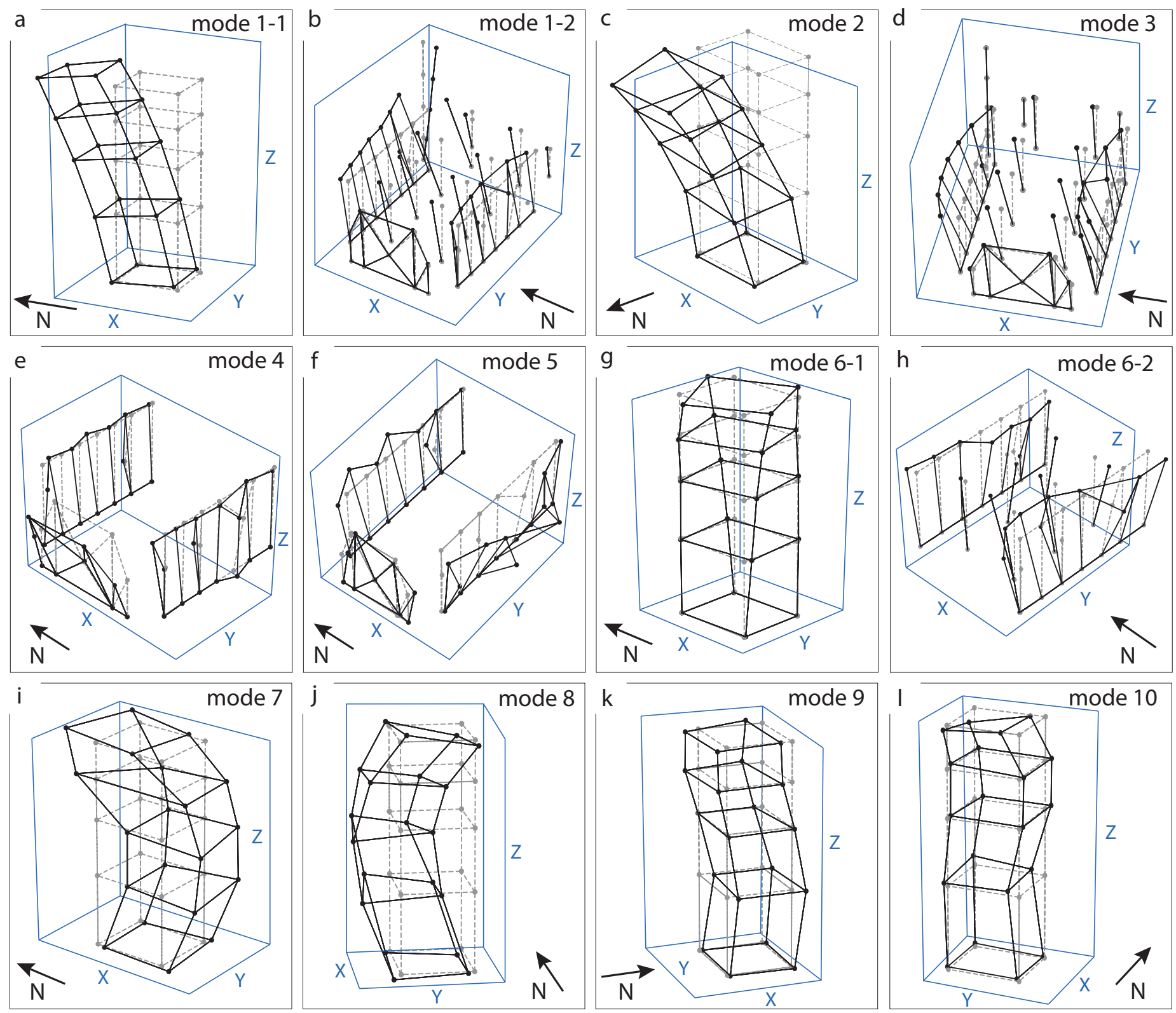

Figure 11: Mode shapes are associated with the selected peaks of the singular values extracted from the singular vector matrices. Dashed gray lines highlight the setup strategy. Black lines are related to the extracted mode shape. The black arrow indicates the North building reference. 

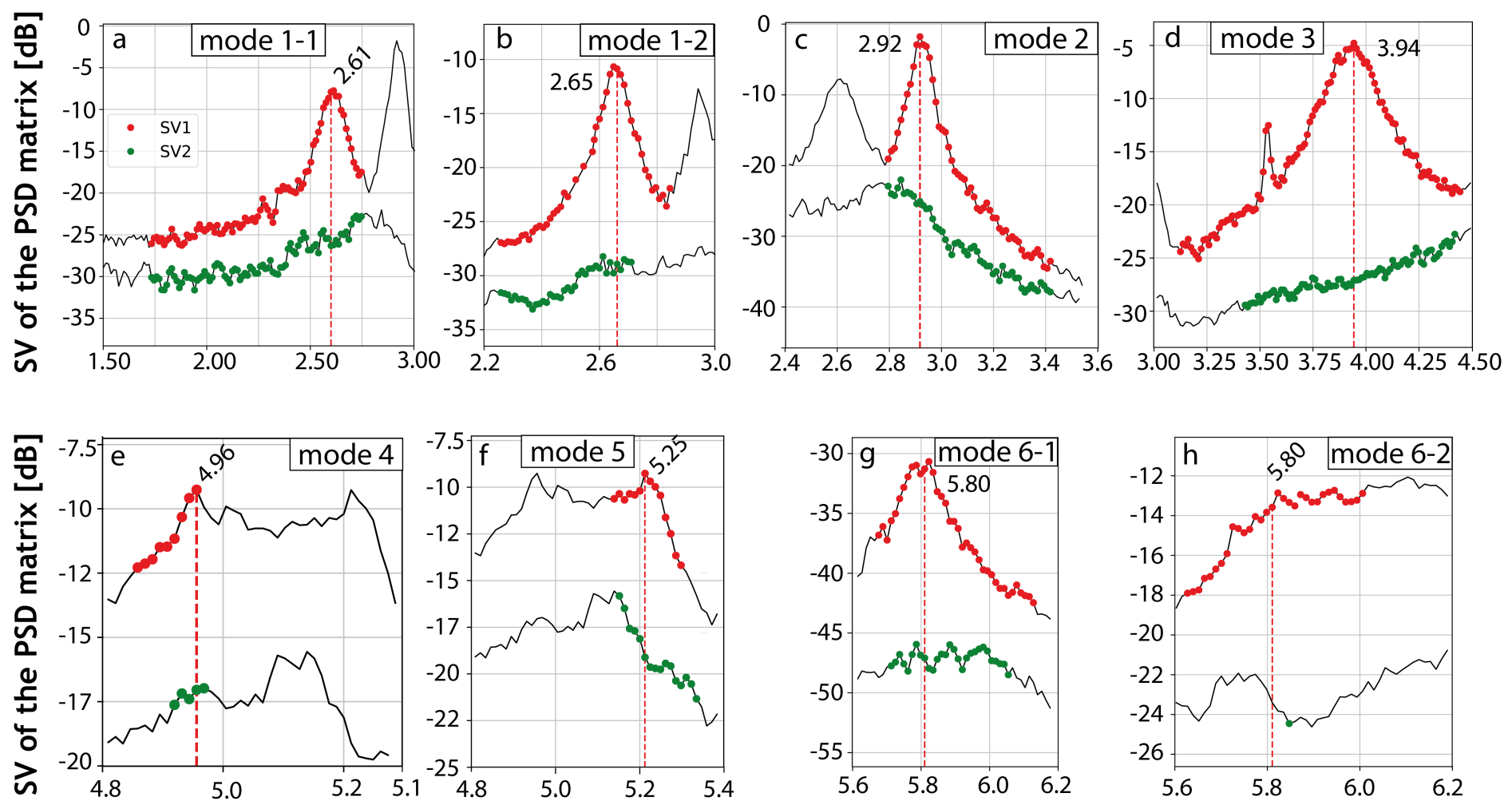

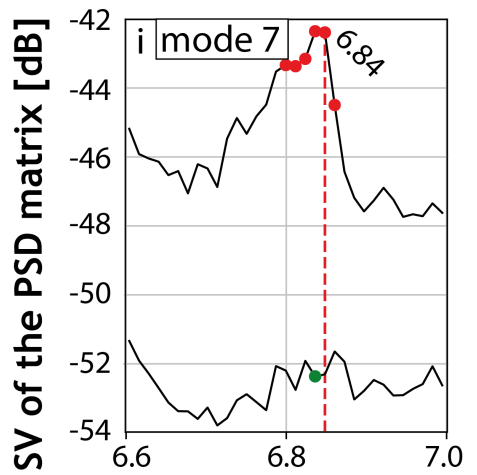

Frequency [Hz]

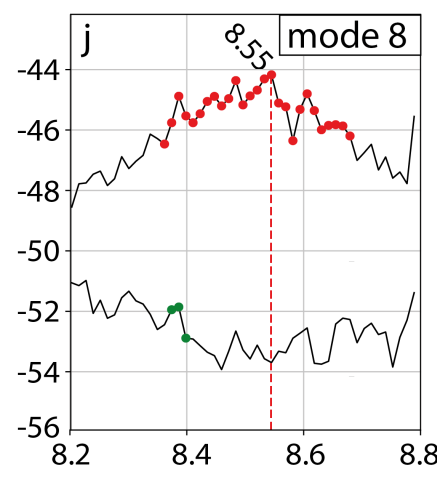

Frequency [Hz]

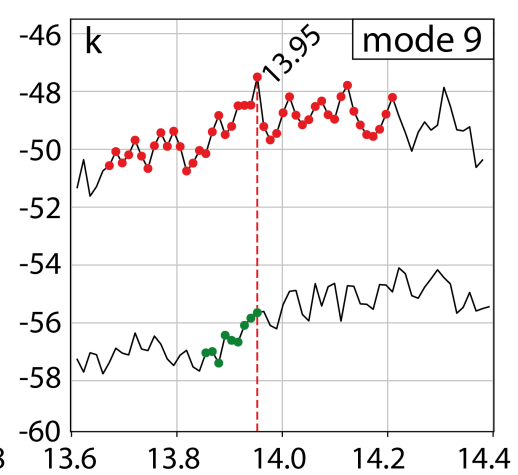

Frequency [Hz]

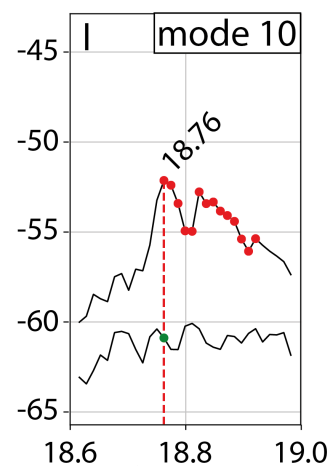

Frequency [Hz]

Figure 12: MAC evaluation close to the picked peak associated with the identified mode. The red dots correspond to the frequencies of the first singular value belonging to the same SDOF density function. The green dots correspond to the frequencies of the second singular value belonging to the same SDOF density function. 


\begin{tabular}{|c|c|c|c|c|c|c|c|}
\hline \multirow{2}{*}{ Mode } & \multirow{2}{*}{ Mode description } & \multicolumn{2}{|c|}{$\begin{array}{l}\text { Frequency }(\mathbf{H z}) \\
f^{B} \\
f^{N}\end{array}$} & \multicolumn{2}{|c|}{$\underset{C^{B}}{\operatorname{Damping}}{\boldsymbol{C ^ { N }}}^{N}(\%)$} & \multicolumn{2}{|c|}{ MCF } \\
\hline & & $f^{B}$ & $f^{N}$ & $\zeta^{B}$ & $\zeta^{N}$ & $M C F^{B}$ & $M C F^{N}$ \\
\hline 1 & $\begin{array}{l}\text { Bending of the bell tower and } \\
\text { nave (North-South) in phase op- } \\
\text { position }\end{array}$ & 2.61 & 2.65 & 1.97 & 2.48 & 0.10 & 0.13 \\
\hline 2 & $\begin{array}{l}\text { Bending of the bell tower and } \\
\text { nave (West-East) }\end{array}$ & 2.92 & 2.95 & 1.00 & 2.52 & 0.15 & - \\
\hline 3 & $\begin{array}{l}\text { Bending of the nave (North- } \\
\text { South) }\end{array}$ & - & 3.94 & - & 2.69 & - & 0.03 \\
\hline 4 & Bending of the facade & - & 4.96 & - & 0.76 & - & 0.37 \\
\hline 5 & Opening of the nave & - & 5.25 & - & 1.19 & - & 0.21 \\
\hline 6 & Torsional mode of the bell tower & 5.82 & 5.82 & 1.15 & 1.11 & 0.17 & 0.03 \\
\hline 7 & $\begin{array}{l}\text { Second bending mode of the bell } \\
\text { tower (North-South) }\end{array}$ & 6.84 & - & 0.24 & - & 0.32 & - \\
\hline 8 & $\begin{array}{l}\text { Second bending mode of the bell } \\
\text { tower along (West-East) }\end{array}$ & 8.55 & - & 0.90 & - & 0.08 & - \\
\hline 9 & $\begin{array}{l}\text { Third bending mode of the bell } \\
\text { tower (North-South) }\end{array}$ & 13.95 & - & 0.61 & - & 0.19 & - \\
\hline 10 & $\begin{array}{l}\text { Third bending mode of the bell } \\
\text { tower (West-East) }\end{array}$ & 18.76 & - & 0.19 & - & 0.41 & - \\
\hline
\end{tabular}

Table 2: Modal parameters of the Sant'Agata del Mugello church extracted from the March and June 2019 ambient vibration measurement campaign by using the EFDD technique. $f^{B}, \zeta^{B}$ and $M C F^{B}\left(f^{N}, \zeta^{N}\right.$ and $\left.M C F^{N}\right)$ correspond to the natural frequency, the damping ratio and the Mode Complex Factor extracted from the March 2019 campaign (the June 2019 campaign, respectively) in the bell tower (in the nave, respectively).

Several low-frequency peaks are identified in the spectrum associated with the June 2019 campaign (peaks in blue below $2 \mathrm{~Hz}$ in Fig. 10). They are not detected during the March 2019 campaign as illustrated in Fig. 9. The three peaks identified at $1.25 \mathrm{~Hz}, 1.42 \mathrm{~Hz}$, and $1.90 \mathrm{~Hz}$ are present on the 6 eigenvalues of the PSD matrix in Fig. 10. They reach an MCF of $0.83,0.99$, and 0.85 , respectively. The peak extracted at $1.34 \mathrm{~Hz}$ is identified only by setups 2, 4, and 6 and reaches an MCF of 0.84 . Two additional peaks are identified at $1.51 \mathrm{~Hz}$ and $2.03 \mathrm{~Hz}$ for all setups and reach an MCF of 0.79 and 0.84. All these MCF values close to 1 argue for classifying these peaks as associated with non-structural vibration modes. Moreover, the MAC computed between the mode shapes associated with the peak frequency and those associated with the surrounding frequencies are below $80 \%$.

All the peaks discussed below have a MCF value close to 0 identifying them as real modes (Table2). The spectrum in Fig. 9 highlights a peak at $f_{1}^{B}=2.61 \mathrm{~Hz}$. The mode shape associated with this peak is a North-South first order bending mode (mode 1-1 in Fig. 11-a). Even the sensors at the base of the bell tower depict a tilt (sensors 610, 620, 630, 640 shown in Fig. 5). Fig. 12-a shows the wide SDOF density function associated to mode 1-1.

A peak is identified at $f_{1}^{N}=2.65 \mathrm{~Hz}$ (Fig. 10) nearby the previous frequency. Its associated mode shape (mode 1-2) is shown in Fig. 11-b. It shows a bending mode of the entire church. The setup installed in the bell tower in June 2019 (sensors 610, 611, 612, 613, and 614 shown in Fig. 7) confirms the bending mode in the North-South direction as shown with mode 1-1. However, the part of the church composed of the nave, the central apse, and the two lateral chapels are bending in phase opposition (mode 1-2) with the mode of the bell tower (mode 1-1).

The second bending mode (mode 2 in Fig. 11-c) in the West-East direction is identified at $f_{2}^{B}=2.92 \mathrm{~Hz}$ (Fig. 9) and $f_{2}^{N}=2.95 \mathrm{~Hz}$. The SDOF distribution (Fig. 12-c) is largely distributed in the neighborhood of this frequency. A tilting of the base of the bell tower is again detected.

The frequency peak at $f_{3}^{N}=3.94 \mathrm{~Hz}$ (Fig. 10) is related to mode 3 (Fig. 11-d). The MAC test (Fig. 12-d) confirms the mode in a wide neighborhood around the peak. This mode corresponds to a bending of the north and south walls of the nave (Fig. 11). The building columns also record this bending but the sensors installed in the bell tower do not highlight any motion. The spectrum in Fig. 9 shows a peak at $f_{3}^{B}=3.81 \mathrm{~Hz}$ close to $f_{3}^{N}=3.94 \mathrm{~Hz}$. The MAC value computed at $f_{3}^{B}$ is however below $80 \%$. 
Two closely spaced modes are observed between $4.96 \mathrm{~Hz}$ and $5.25 \mathrm{~Hz}$ (Fig. 10) related to mode 4 (Fig. 11-e) and mode 5 (Fig. 11-f). The MAC is used to discriminate the SDOF distribution of these two modes (Fig. 12-e and -f). A first peak is identified in Fig. 10 at $f_{4}^{N}=4.96 \mathrm{~Hz}$. Mode 4 shows a tilting of the church facade (Fig. 11-e). This natural frequency highlighting a mode of the nave is identified in the SV1 spectrum shown in Fig. 9 at

$f_{4}^{B}=4.83 \mathrm{~Hz}$. The MAC value is obviously too small to identify a mode shape associated to the bell tower. The second peak is observed at $f_{5}^{N}=5.25 \mathrm{~Hz}$ (Fig. 10). The associated mode shape highlights an opening mode of the church (Fig. 11-f).

Mode 6 is a torsional mode affecting the bell tower (mode 6-1 in Fig. 11-g) and the nave (mode 6-2 in Fig. Fig. 11-h) identified at $f_{6}^{B}=5.82 \mathrm{~Hz}$ on the spectrum shown in Fig. 9 and $f_{6}^{N}=5.82$ on the spectrum illustrated in Fig. 10.

Mode 7 identified at $f_{7}^{B}=6.84 \mathrm{~Hz}$ corresponds to a second-order bending mode of the bell tower towards the North-South direction (Fig. 11-i). As for the first bending mode of the bell tower in the North-South direction (mode 1-1 in Fig. 11-a), a tilting of the base of the bell tower is also observed. The second order bending mode (mode 8 ) of the bell tower in the West-East direction (Fig. 11-j) is identified at $f_{7}^{B}=8.55 \mathrm{~Hz}$ in Fig. 9. The tilting of the base of the bell tower is again observed.

Third order bending modes of the bell tower were also observed (Fig. 9). Mode 9 is identified at $f_{9}^{B}=13.95 \mathrm{~Hz}$ and mode 10 at $f_{10}^{B}=18.76 \mathrm{~Hz}$. The two modes are confirmed with the wide SDOF distribution (Fig. 12-k, l).

\section{Discussion about the modal parameters}

The modes of the church are now discussed, paying attention to the modes peculiarities in relation with the building history.

The low-frequency peaks below $2 \mathrm{~Hz}$ (Fig. 10) are undoubtedly related to transient sources, not reflecting a normal mode behavior of the structure. First, they reach MCF values close to 1, identifying them as imaginary modes. Second, they do not appear among the singular values of the PSD matrices of the March 2019 campaign. Each peak presents peculiarities, moreover. Peaks at $1.25 \mathrm{~Hz}, 1.42 \mathrm{~Hz}$, and $1.90 \mathrm{~Hz}$ are present on all PSD matrix eigenvalues, proving that they do not have a structural but an anthropogenic origin. The $1.34 \mathrm{~Hz}$ peak appears only on setups 2,4 , and 6 , which were recorded during a water pump located $500 \mathrm{~m}$ from the church. Finally, the SDOF density functions associated with the peaks identified at $1.51 \mathrm{~Hz}$ and $2.03 \mathrm{~Hz}$ are not conclusive (only one frequency point corresponds to the same selected mode).

$f_{1}^{B}$ and $f_{1}^{N}$ correspond to the same natural frequency of mode 1-1. The slight difference in frequency $(\delta f=$ $0.04 \mathrm{~Hz}$ ) is likely related to the different weather conditions between the two surveys. Carried out at the end of winter, temperatures around $10{ }^{\circ} \mathrm{C}$ and significant wind gusts characterized the March 2019 survey. On the contrary, the June 2019 survey was conducted under temperatures around $35{ }^{\circ} \mathrm{C}$ with no wind.

If modal parameters provide information about the overall behavior of the church, they also give more localized information. As an example, mode 1-1, mode 2, mode 7, and mode 8 show a rocking behavior of the bell tower, which may induce Soil-Structure Interaction. Moreover, it is crucial to constrain better the boundary conditions between the ground and the church in the case of an optimization process of a numerical model.

The phase opposition between mode 1-1 and mode 1-2 highlights the weak mechanical coupling between the bell tower and the nave. This observation is supported by a stratigraphic analysis provided in a previous study [3] demonstrating the late construction of the bell tower at least three centuries after the nave. Only a mortar joint between the bell tower and the northern wall of the nave was identified [3] which could induce the observed mode. Mode 1-2 highlights thus the profound impact of the building's history on its dynamic behavior. It also emphasizes the importance of setting up synchronous measurements common to the nave and the bell tower based on previous stratigraphic analysis.

The weak coupling between the bell tower and the nave can also be seen with mode $3\left(f_{3}^{N}=3.94 \mathrm{~Hz}\right)$. The sensors present in the bell tower do not register any movement even if the peak is also detected at $3.81 \mathrm{~Hz}$ (Fig. 9).

Mode 4 and mode 5 are compatible with the titling of the main facade and the southern and northern wall of the nave induced by the 1542 earthquake as observed thanks to the stratigraphic analysis [3]. These two modes can potentially activate the tilting of the three walls making the nave a vulnerable place in case of an earthquake. The upper part of the mode shape of mode 5 is not homogeneously distributed. As an example, sensors 1213 and 1215 (sensor at level 2 in the northern wall shown in Fig. 7) show a relative displacement that is small compared to 
what would be expected for an opening mode. The recording environment may be the cause of this phenomenon. The sensors in the upper part had to be installed on the beams of the wooden frame in the absence of another possibility. This increases the uncertainty of the mode identification and is a limitation of the study.

The two third-order bending modes identified (modes 9 and 10) reach the spatial resolution limit allowed by the sensor setups.

The damping values between $0.19 \%$ and $2.69 \%$ are consistent with the literature. We notice that the damping values are lower for the higher-order modes than for the lower ones. It can be explained by the difficulty in identifying a damping value to fit the IRF. This value varies mainly depending on the time window selected to fit the curve. We also observe a shift in the damping values between the nave and the bell tower for the same modes. This shift can be explained by the differences in construction techniques used in these two parts of the building [3]. The weather conditions could also have influenced the results. This is a topic for further study.

Beyond the identification of the modal parameters of the church of Sant'Agata, the results show the impact of the construction history of the church on its behavior. Indeed, 3 modes out of the 10 identified ones are directly related to the church's past (modes 1, 4 and 5). It raises questions about the instrumentation strategy's effectiveness in identifying such fundamental singularities. We propose below a brief reflection on the impact of the instrumentation strategy on the identification of these singularities.

\section{The impact of the setup design}

Although the optimal sensor placement for vibration measurements is not the objective of the work, we take advantage of the high number of sensors used in the two instrumental campaigns as a feedback to discuss the impact of the sensor placement imposed by the measurement conditions on the modal parameters identification and more specifically on the mode shape.

Two criteria are used: the autoModal Assurance Criterion (autoMAC, [83]) and the Coordinate Modal Assurance Criterion (CoMAC, [84]). The autoMAC consists in computing the MAC criterion (Eq. 12) of the same modal base, here the experimental one. In particular, it allows checking the ability of the sensor system to precisely separate the modes. If two eigenmodes are correctly identified through EFDD, the MAC should be close to zero since they are orthogonal. If the number of sensors is insufficient or poorly positioned, the orthogonality of two eigenmodes will not be detected correctly. In this way, autoMAC is an efficient criterion for evaluating the relevance of a sensor placement strategy at first order.

A more detailed approach can be made using the CoMAC. The CoMAC is a local measurement of the similarity between the two modal bases for each degree of freedom. We use this criterion to compare modal bases obtained from different sensor placement strategies. Its expression is the following for the degree of freedom $q$, with $r$ the mode number, and $N_{m}$ the number of mode pairs forming the two modal bases $\{\Phi\}$ and $\{\Psi\}$ :

$$
\operatorname{CoMAC}(q)=\frac{\sum_{r=1}^{N_{m}}\left|\Psi_{q}^{r} \Phi_{q}^{r}\right|^{N}}{\sum_{r=1}^{N_{m}}\left(\Psi_{q}^{r}\right)^{2} \sum_{r=1}^{N_{m}}\left(\Phi_{q}^{r}\right)^{2}}
$$




\subsection{The March 2019 campaign}
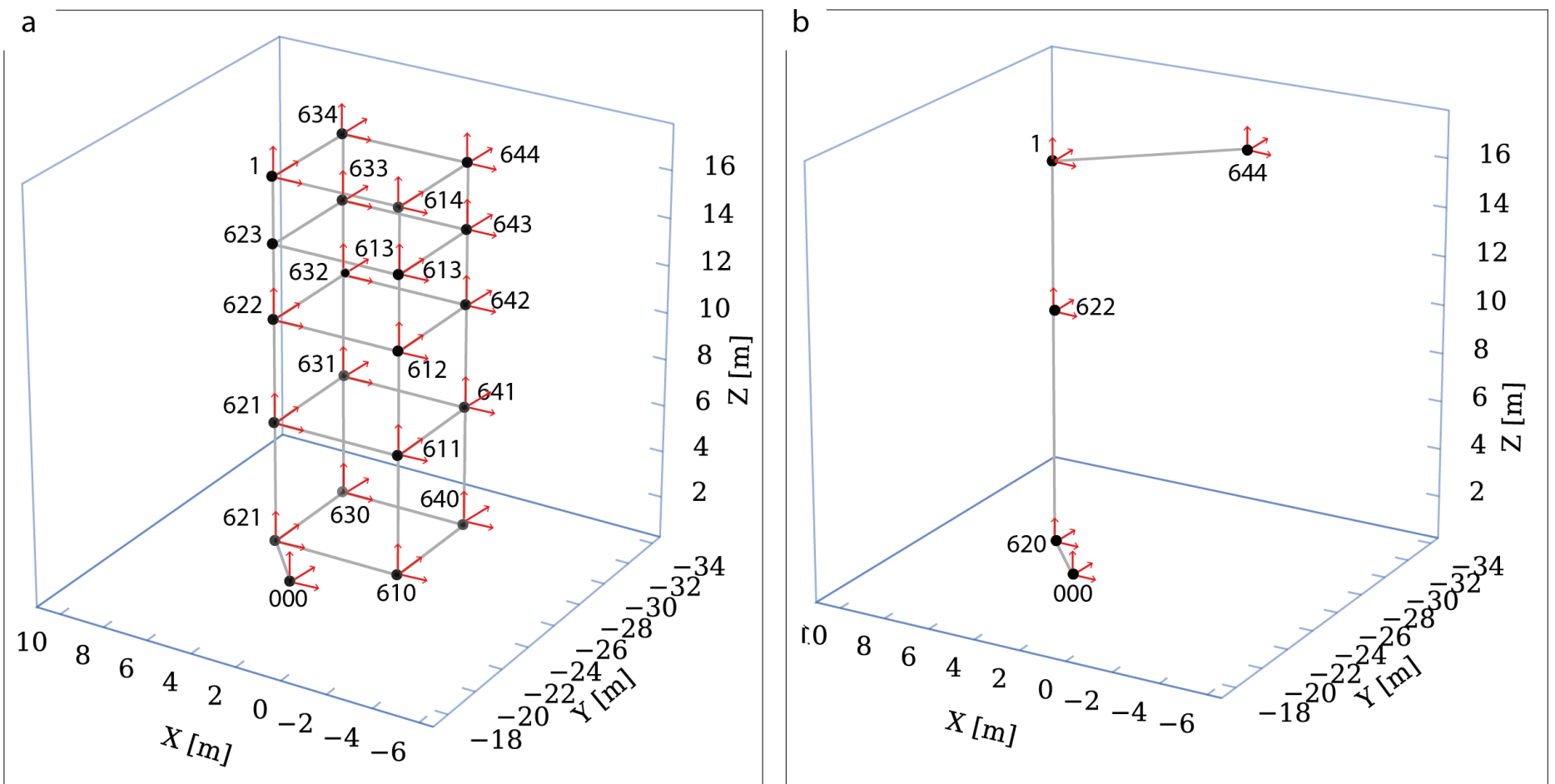

Figure 13: a - Strategy SB0: setup design used in March 2019. b - Strategy SB1: alternative setup design for the survey in March 2019.
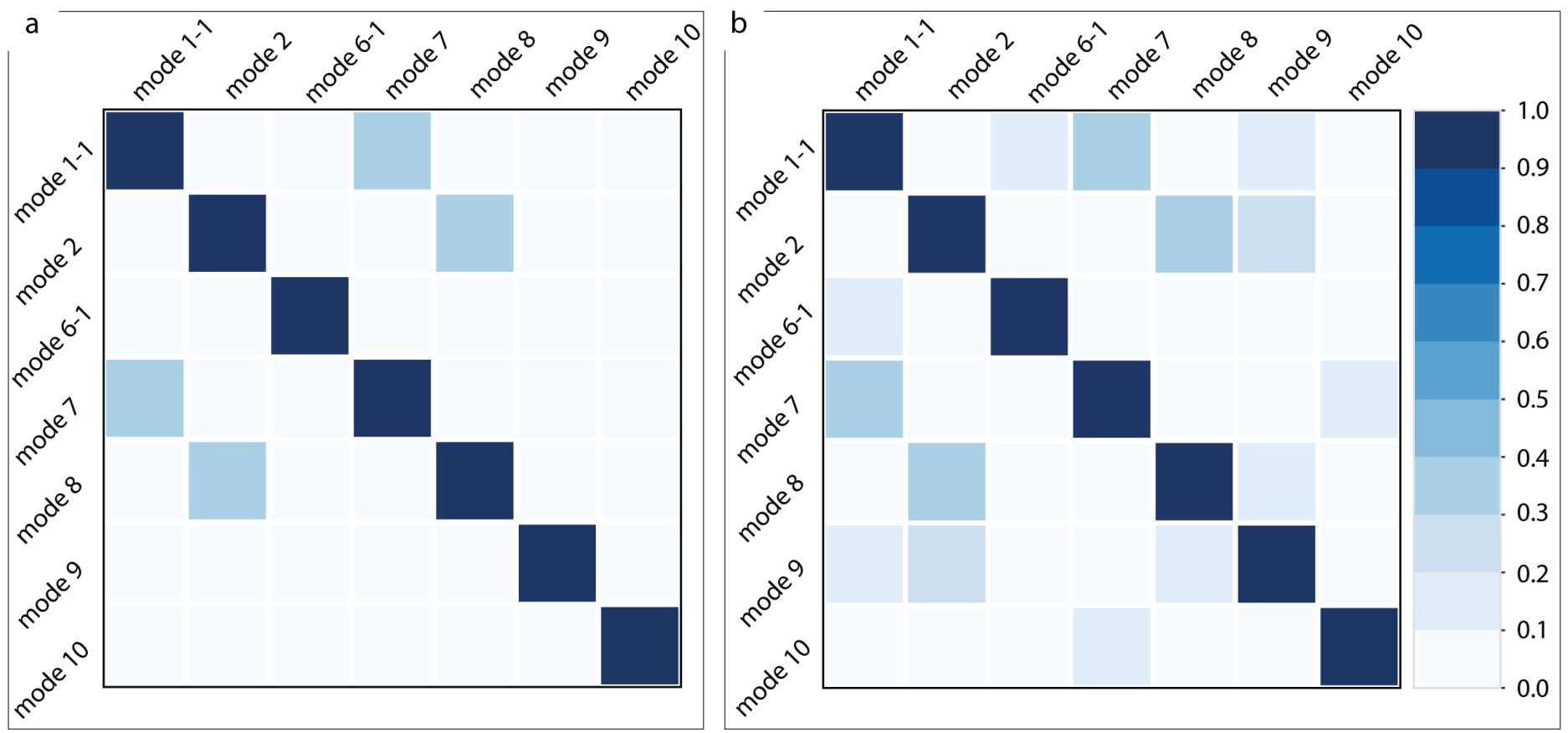

Figure 14: a - AutoMAC related to strategy SB0. b - AutoMAC related to strategy SB1.

The sensor placement strategy (SB0) using 21 tri-axial sensors (63 DoFs) applied during the March 2019 campaign is shown in Fig. 13-a. Fig. 14-a illustrated the autoMAC matrix for the SB0 strategy. The correlation between the modes of the same modal base is less than $40 \%$. The highest correlations are only for pairs of modes: mode 1-1/mode 7 (35.0\%) and mode 2/mode 8 (37.3\%). By contrast, an alternative strategy SB1 (Fig. 13-b) using only 

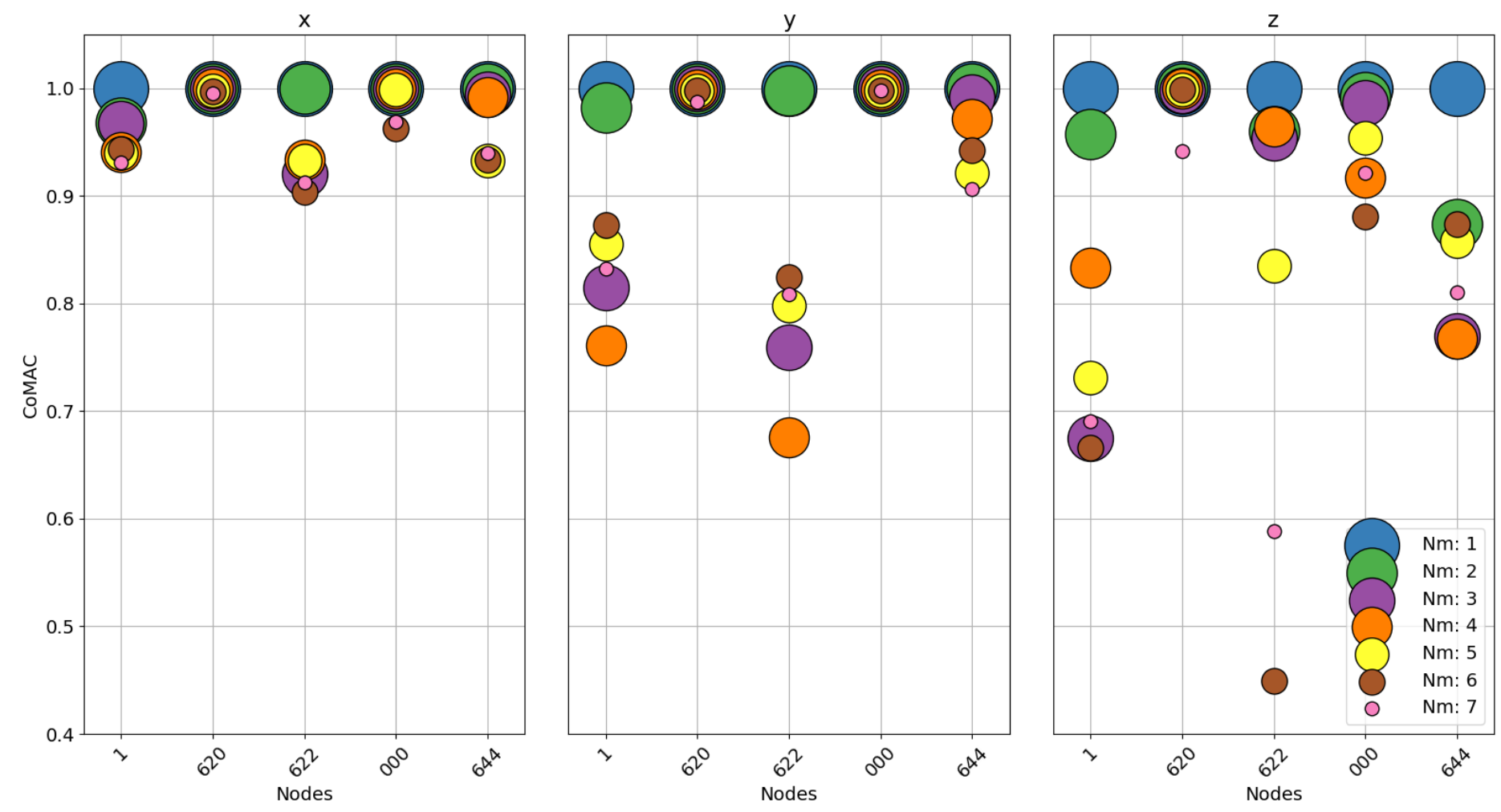

Figure 15: CoMAC between the nodes common to strategy 0 (SB0) and strategy 1 (SB1). Each column corresponds to the degree of freedom of the considered sensor $(\mathrm{x}, \mathrm{y}, \mathrm{z})$. The sensor number is indicated on the $x$-axis. The $N_{m}=7$ modes are used to compute the CoMAC.

5 tri-axial sensors (15 DoFs) is tested. This sensor placement strategy is often used as a minimal configuration to identify the first modes [15, 64]. The autoMAC matrix of the SB1 strategy (Fig. 14-b) shows again MAC values below $40 \%$ between the pairs of modes of the experimental base. However, the MAC value is higher for some mode pairs for the SB1 strategy than for the SB0 strategy. As an example, $\mathrm{MAC}\left(\left\{\phi_{1-1}\right\},\left\{\phi_{6-1}\right\}\right)=16.0 \%$ in SB1 strategy whereas $\operatorname{MAC}\left(\left\{\phi_{1-1}\right\},\left\{\phi_{6-1}\right\}\right)=0.02 \%$ in SB0 strategy.

The CoMAC is now computed to analyze the impact of the design setup on the mode shape identification at the scale of the degrees of freedom common to both strategies SB0 and SB1 (Fig. 15). It was calculated according to Eq. 5 considering an increasing number of modes $N_{m}$ ranging from 1 to 7 modes among mode 1-1, mode 2, mode 6-1, mode 7, mode 8, mode 9, and mode 10 corresponding to the modes of the bell tower (first and second-order bending modes in the two orthogonal directions and the torsional mode) identified during the March 2019 campaign. In general, we observe a high correlation when the first mode alone is considered $\left(N_{m} \in[1,2]\right)$. For each sensor position, the CoMAC decreases when the number of compared modes $\left(N_{m}\right)$ decreases. Those results are characteristic of the drop in spatial resolution of the sensor placement strategy for higher-order modes. For the $x$ degree of freedom (North direction), the correlation remains above $85 \%$. For the $y$ degree of freedom (West-East direction), the mode shape correlation obtained at nodes 1 (level 4 of the bell tower) and 622 (level 2 of the bell tower) are lower than $85 \%$ as soon as three modes are considered in the CoMAC calculation $\left(N_{m}=3\right)$. The minimum correlation is $67 \%$ at node 622 when $N_{m}=4$ modes are used in the calculation.

The CoMAC value of the degree of freedom z (vertical) undergoes the lowest correlation. It shows the lowest values: $45 \%$ correlation at node 622 considering $N_{m}=6$ modes.

\subsection{The June 2019 campaign}

Strategies of instrumentation of the nave SN0 and SN1 are compared (Fig. 16). SN1 is an alternative strategy with less sensors (Fig. 16-b). In the SN1 strategy, level 2 is not instrumented. In other words, this strategy corresponds to the position that the sensors would have had if the "spider" aerial platform had not been used. We observe that $\operatorname{MAC}\left(\left\{\phi_{1-2}\right\},\left\{\phi_{3}\right\}\right)=48.4 \%$ (Fig. 17-a). For the other pairs of modes, the MAC is less than $1.6 \%$. The autoMAC 
of SN1 shows that only 4 modes (mode 1-2, mode 3, mode 4 and mode 6-2) composed the modal base (Fig. 17-b). The alternative SN1 strategy does not allow to identify mode 5 . The pair of mode mode1-2/mode 3 presents the most important MAC value (34.7\%). The other MAC values are lower than $1.6 \%$.
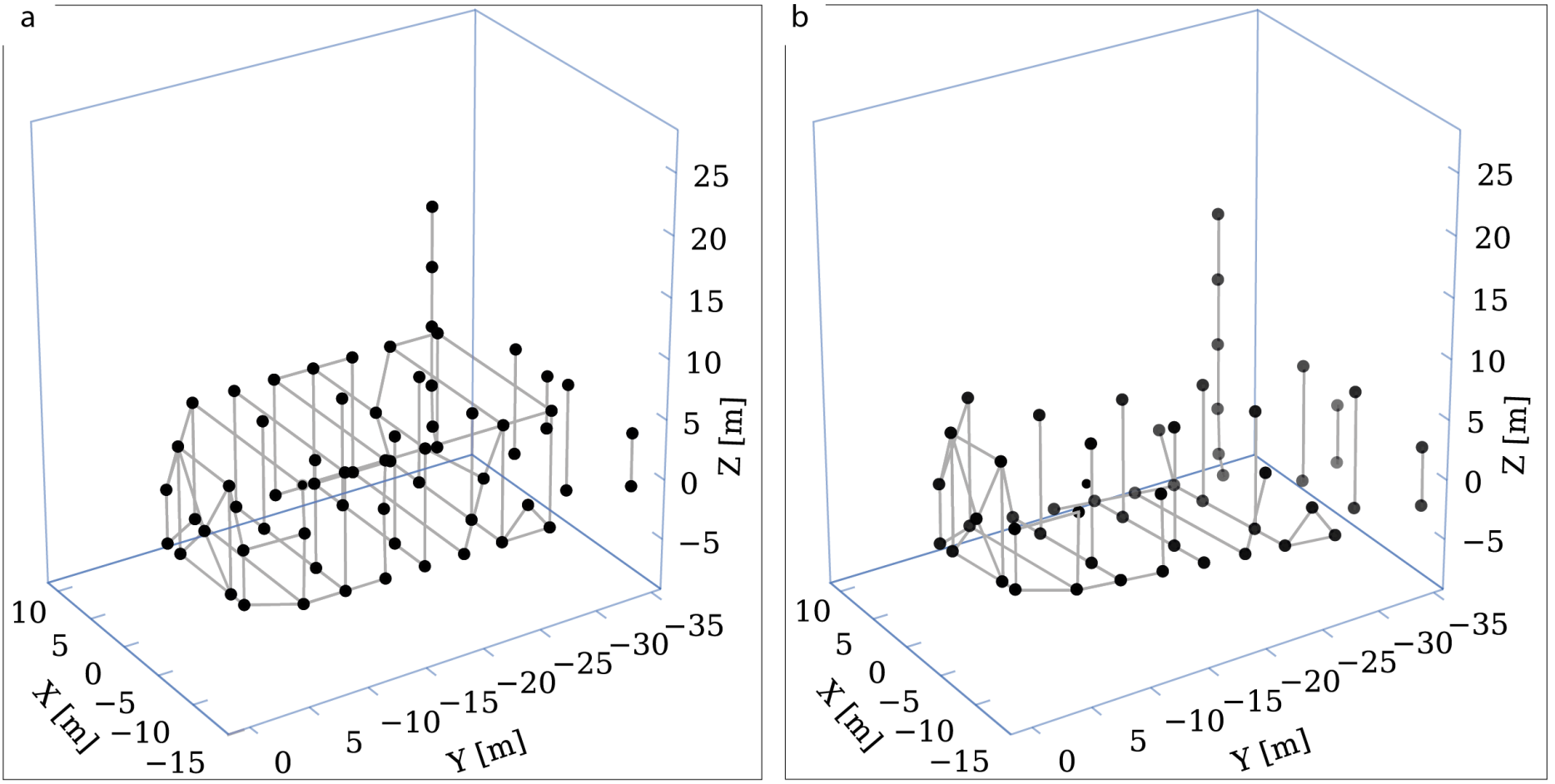

Figure 16: a - Strategy SN0: sensor system used in June 2019. b - Strategy SN1: alternative sensor system used to perform OMA from the survey in June 2019 by removing the majority of sensors of level 2 that are inaccessible without the "spider" aerial platform.
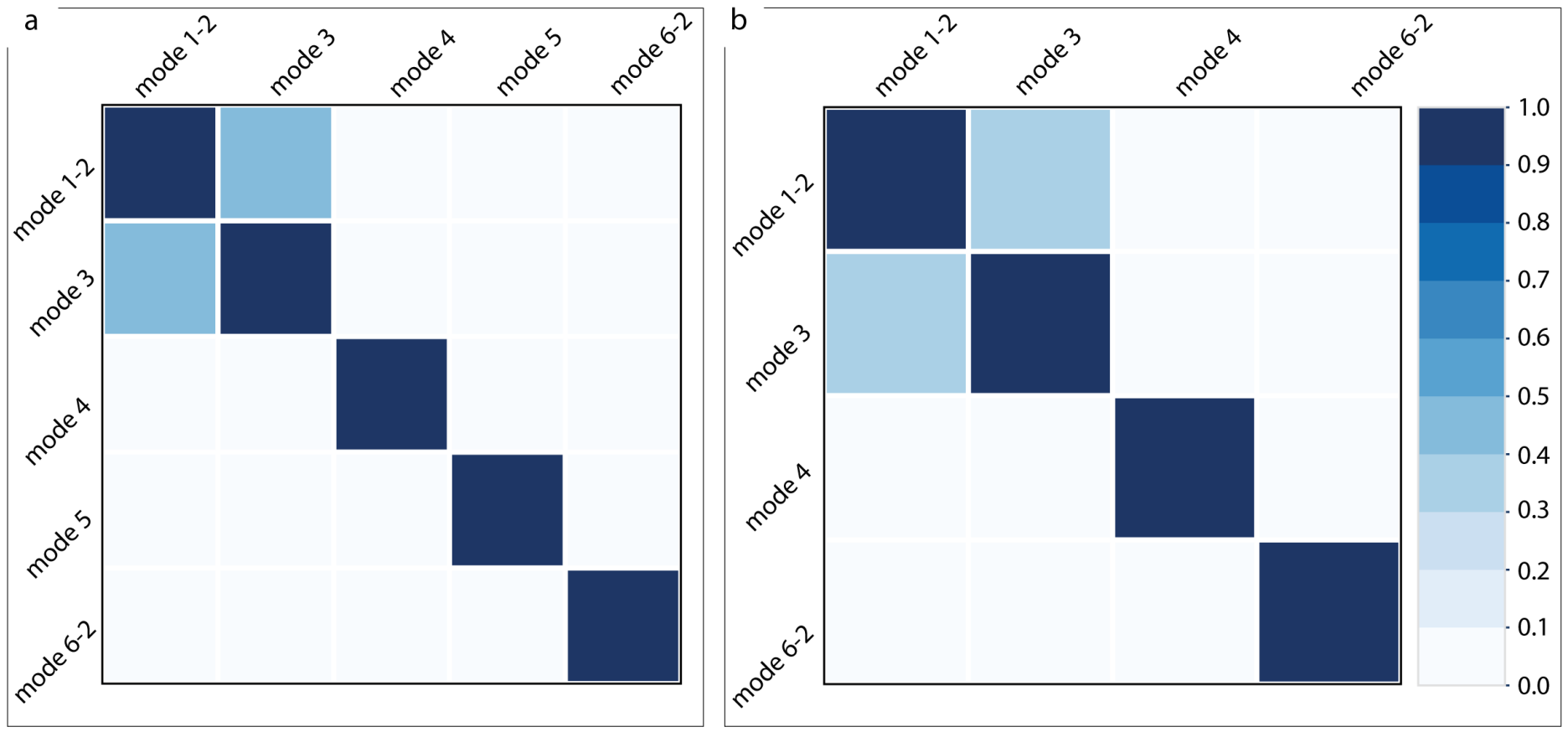

Figure 17: a - AutoMAC related to strategy SN0. b - AutoMAC related to strategy SN1.

Fig. 18 shows the value of the CoMAC calculated from the two experimental bases of the two strategies, SN0 and SN1. This value only takes into account $N_{m}=4$ modes since mode 5 was not detected by the SN1 strategy. 
Considering only mode 1-2 (bending mode of the nave) identified by both strategies, the CoMAC shows a strong correlation for all degrees of freedom. When mode 1-2 and mode 3 (flexural mode of the nave in the North-South direction) are used (mode 1-2, mode 3), the CoMAC value drops for the $y$ and $z$ directions. In the $y$ direction, the minimum correlation level $(60.5 \%)$ is reached for sensor 4120 (sensor installed at level 1 in the south corner of the facade of the nave). However, it remains above $80 \%$ in the z-direction. When $N_{m}=3$ modes are used (mode 1-2, mode 3 and mode 4), the CoMAC keeps a high value above $79 \%$ whatever the degree of freedom considered. When all modes are used $\left(N_{m}=4\right.$ with mode 1-2, mode 3, mode 4 and mode 6 -2), a large variation of the CoMAC value is observed. 28 degrees of freedom have a CoMAC value lower than $80 \%$ (17\% of the degrees of freedom of the SN0 strategy).

\section{Discussion about the setup design}

The autoMAC matrix of the SB0 strategy confirms the ability of the sensor placement strategy used during the March 2019 campaign to separate the 7 modes. For the SB1 strategy, even if the separation of modes succeeded, we note that the density of sensors strongly influences the separation capacity. The SB1 sensor placement strategy provides a correlation of $16 \%$ between a bending mode (mode 1-1) and a torsion mode (mode 6-1), while the SB0 strategy identifies the orthogonality between the two modes.

Moreover, the value of the CoMAC drops when integrating the higher-order modes (from mode 6-1). This demonstrates that the identification of mode shapes of the higher-order modes are different from a sensor placement strategy to another. It highlights the importance of a high enough sensor density to identify mode shapes correctly. This difference can have a significant impact. In the context of Structural Health Monitoring, an incorrect evaluation of the mode shapes can have consequences on the interpretation of the dynamic behavior of the building and the interpretation of potential damage.

Modal parameters are often used in vibration-based model updating to update numerical models. The material properties of the model are then optimized by minimizing the difference between the experimental and the numerical modal parameters extracted from the model. A lower sensor density decreases the spatial discretization of the mode shapes. These mode shapes obtained with a poorer resolution will induce a bias in the numerical optimization of the model parameters (boundary conditions, ....).

Beyond the evaluation of modal parameters, the reference SB0 strategy performed during the 2019 March campaign identified a rocking of the bell tower base. This information can lead us in future works to model the interface between the bell tower and the ground and update its rigidity as a boundary condition. This tilting is not detected by the alternative SB1 strategy, which again, induces a loss of information either on the behavior of the structure or to calibrate the boundary conditions.

The autoMAC shown in Fig. ,17-a demonstrates the ability of the strategy used during the June 2019 campaign (SN0 strategy) to separate the modes correctly. Although mode 1-2 is identified in SN1, the lack of a sensor at the top of the nave does not allow a sufficient resolution to observe the mode shape of the nave. In particular, the application of SN1 would have led to the impossibility of identifying the opposition phase between the nave and the bell tower. This has a crucial impact on the church's vulnerability assessment. Since the information is missing, this can lead to a major error in the modeling process, inducing a bias in the simulation of the seismic response of the church. The second limitation of the SN1 strategy is its inability to detect mode 5. It induces a truncated knowledge of the dynamic behavior of the church. Mode 5 is particularly important since it can potentially activate a pre-existing tilting of the north and south walls of the nave induced by the 1542 earthquake [3].

The use of the only other modes detected by the alternative strategy SN1 (mode 1-2, mode 3, mode 4 and mode 5 shown in Fig. 11) shows a decrease of the CoMAC value when higher frequency modes are taken. The absence of sensors in the upper part of the nave (level 2) strongly impacts the quality of the mode shape. This leads to the same consequences as for the previous strategy.

Alternative strategies have been tested by removing sensors in the lower levels (supplementary material). A slight difference in correlation is noted between these alternative strategies and the SN0 strategy, highlighting the importance of densifying records in the highest part of the building again. 

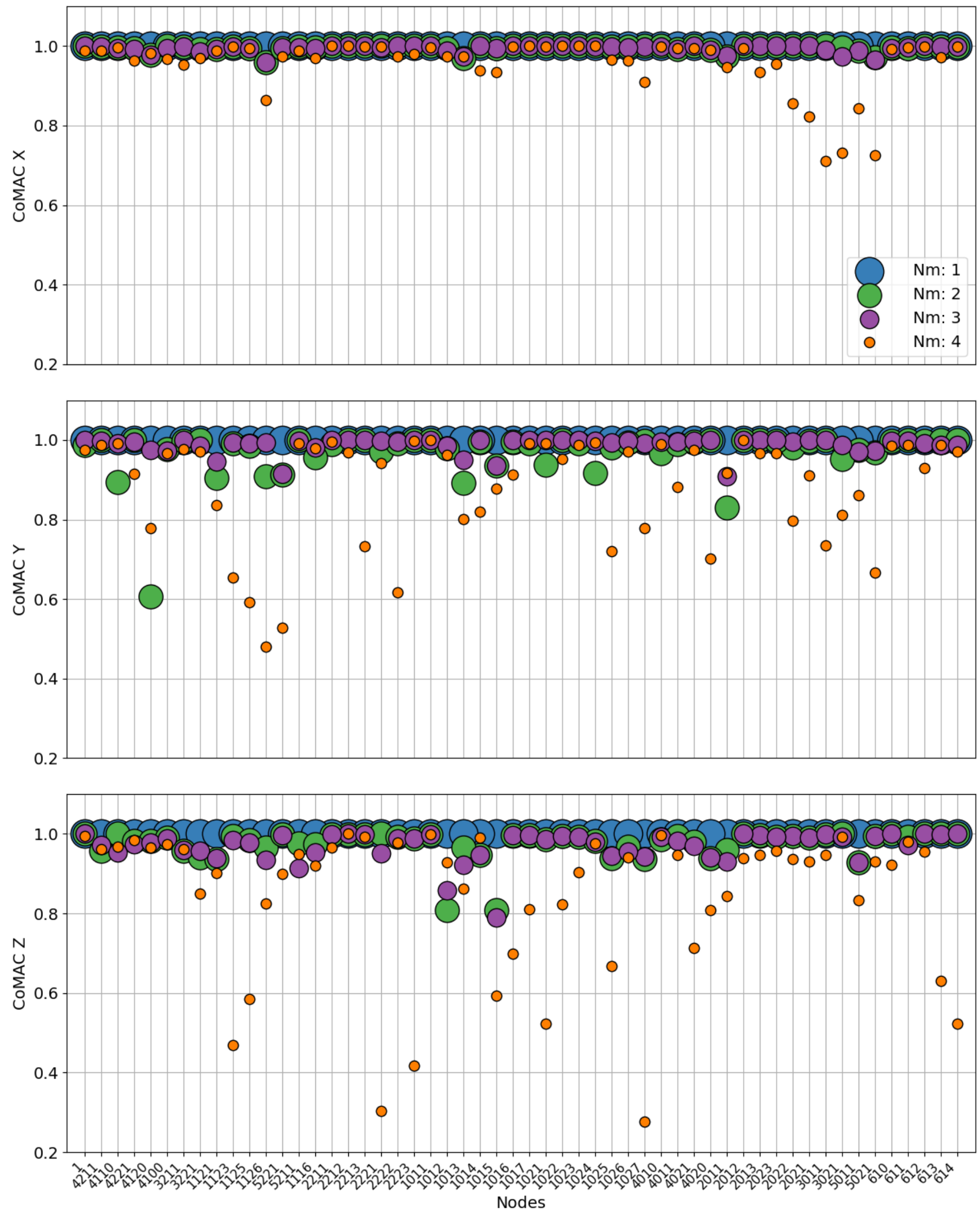

Figure 18: CoMAC between the nodes common to stategy 0 (SN0) and strategy 1 (SN1) of the 2019 June campaign. $N_{m}=4$ modes are used to compute the CoMAC. 


\section{Conclusions}

This paper focuses on the structural identification of the medieval church of Sant'Agata del Mugello. This Cultural Heritage building has a rich and complex constructive history. The bell tower was built at least 3 centuries after the nave. The earthquake of 1542 caused a tilting of the walls of the nave. Many repair operations followed over the centuries [3].

Two dense ambient vibration campaigns were performed in March and June 2019. The modal parameters associated with 10 modes were extracted using the Enhanced Frequency Domain Decomposition technique. The March 2019 campaign allowed a dense characterization of the bell tower. 7 modes have been extracted. The June 2019 campaign aimed to instrument the whole church. The major technical challenge of this campaign was the instrumentation of the upper part of the nave. A "spider" aerial platform was used to instrument the wooden frame of the church as close as possible to the walls of the nave. This operation allowed us to identify 3 additional modes (mode 3, mode 4, and mode 5) and to detail 2 modes identified during the March 2019 campaign: the bending mode 1-2 associated with the bending mode of the bell tower mode 1 and the torsional mode 6-2 associated to the torsional mode of the bell tower mode 6-1.

We show that the peculiarities of some modes (mode 1, mode 4, and mode 5) can be explained by the constructive history of Sant'Agata del Mugello. The pounding effect induced by mode 1 is related to the late construction of the bell tower. The bending of the three external walls of the nave (modes 4 and 5) agrees with the flexural and torsional modes of the church.

Slight tilting of the bell tower base was identified with the first bending modes of the bell tower (mode 1 and mode 2). This information will be essential to consider for modeling the soil-structure interaction and updating the boundary condition of a future digital model.

This study provides the opportunity to retrospectively test the impact of several basic sensor placement strategies on the resolution of the identified modal parameters.

In the specific case of Sant'Agata del Mugello, we have observed that a minimally designed sensor placement strategy fails to detect specific modes (no detection of mode 5 using the SN1 strategy or induce a drop in resolution in the identification of some modes. The phase opposition of mode 1-2 is detected thanks to the dense instrumentation of the interface between the nave and the bell tower. The instrumentation, although difficult, was therefore of decisive importance.

This case study confirms that the level of knowledge of the constructive history is an essential factor to have a better understanding of the dynamic properties of the building consistent with ICOMOS guidelines [4]. We recommend then densifying the number of measurements near the architectural discontinuities of the building. In the case of Sant'Agata, this concerns the areas that have been rebuilt (upper parts of the nave) at the interface with the bell tower.

In future work, the experimental modal parameters and the knowledge of the constructive history of Sant'Agata del Mugello will be used to update uncertain structural parameters like the material properties of the main building phases [3] and the boundary conditions (interface between the bell tower and the nave or between the bell tower and the ground). This model will be used for a first evaluation of the vulnerability of the church for low seismic loads.

The studies of sensor placement presented in the specific case of Sant'Agata del Mugello could be improved by using a dedicated Optimal Sensor Placement strategy [85] including features given by the constructive history of the building.

\section{Acknowledgments}

The authors thank Hélène Dessales for advice during the development of this research work and comments on an early version of the manuscript. We thanks the members of the GT RAP MoVIng group for advising this project. The work greatly benefited from the support of Anne Mangeney and the ERC-CG-2013-PE10-617472 SLIDEQUAKE, who provided the Lennartz seismometers and Philippe Guéguen for his advice on the placement of the sensors. We thank Francesco Libone and his team in charge of the spider, Andrea Arrighetti, for the discussions about the results. The authors warmly thank the community of Sant'Agata del Mugello for their moral and logistic support, in particular, the major Federico Ignesti, Don Gianluca Mozzi, Marco Casati, Filippo Bellandi, Paolo Gucci and Anna Bambi. 
This work was funded by Institut de Radioprotection et de Sûreté Nucléaire, Ecole Normale Supérieure and the program TelluS-ALEAS of INSU-CNRS.

\section{Supplementary material}

This appendix details two additional alternative strategies tested called SN2 and SN3. The strategy SN2 intended to instrument one wood beam out of two (sensors 1212, 1214, 1216, 1222, 1224 and 1226 were removed from level 2, Fig. 7). Mode 5 was successfully identified but also led to a decrease in the correlation between modes compared to the SN0 strategy at the scale of degree of freedom (Fig. A. 1). CoMAC decay involves fewer sensors than the SN1 strategy. The sensors concerned are mainly in the two lateral chapels (5011, 5021, and 3011). The value of the CoMAC between the two modal bases for all degrees of freedom positioned on the beams of the wood frame remains greater than $80 \%$. It means that the SN1 sensor placement strategy had a small impact on the quality of the mode shapes. The strategy SN2 is thus accurate enough to identify modal parameters.

The sensor placement strategy SN3 excluded sensors from level 1 (sensors 1116, 1121, 1123, 1125, and 1126 are removed from level 1). Only a very slight drop of the CoMAC has been noted (Fig. B. 1, the value of the CoMAC is higher than $95 \%$ whatever the degree of freedom considered). This strategy had a small impact on the quality of the mode shapes again. 

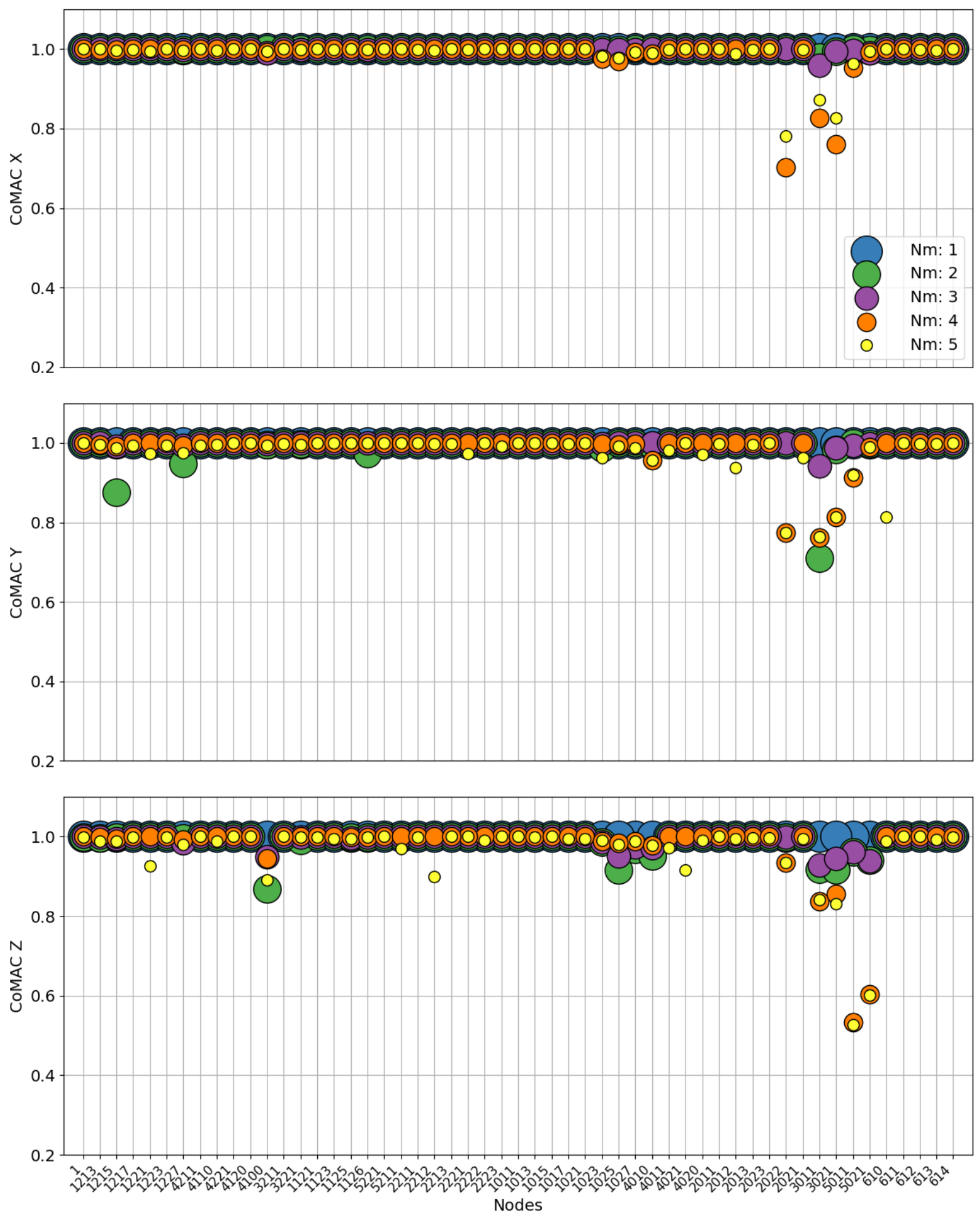

Figure A. 1: CoMAC between the nodes common to stategy 0 (SN0) and strategy 2 (SN2) of the 2019 June campaign. $N_{m}=5$ modes are used to compute the CoMAC. 

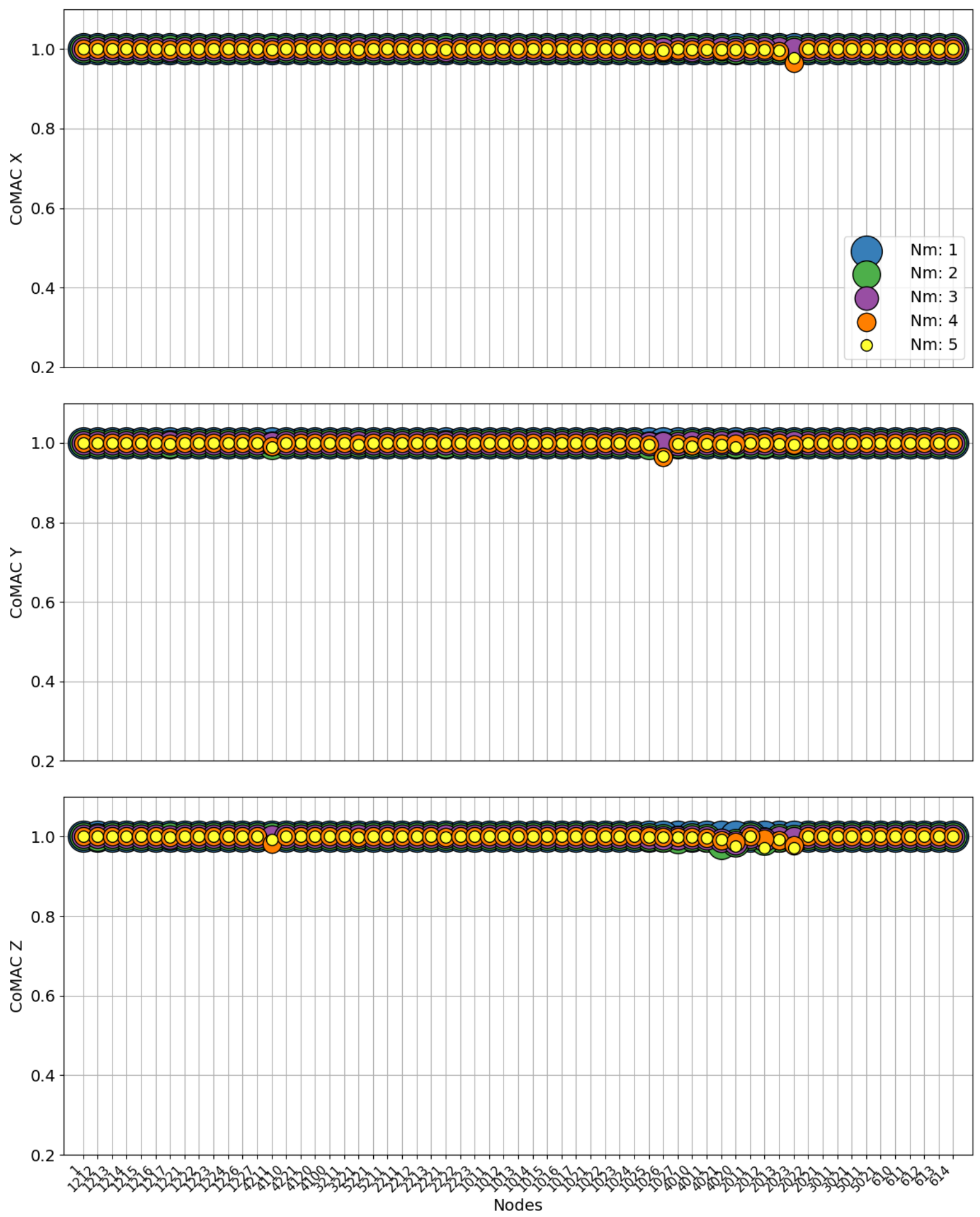

Figure B. 1: CoMAC between the nodes common to stategy 0 (SN0) and strategy 3 (SN3) of the 2019 June campaign. $N_{m}=5$ modes are used to compute the CoMAC. 


\section{References}

[1] Antonella Saisi, Carmelo Gentile, and Marco Guidobaldi. Post-earthquake continuous dynamic monitoring of the gabbia tower in mantua, italy. 81:101-112, April 2015, doi:10.1016/j.conbuildmat.2015.02.010.

[2] Ali Al-Ghalib, Fouad Mohammad, Mujib Rahman, and John Chilton. Damage and repair quantification in reinforced concrete beams using vibration data. pages 575-584. CRC Press, September 2011.

[3] Arnaud Montabert, Hélène Dessales, Andrea Arrighetti, Julien Clément, Maria Lancieri, and Hélène Lyon-Caen. Tracing the seismic history of sant'agata del mugello (italy, tuscany) through a crossdisciplinary approach. Journal of Archaeological Science: Reports, 33:102440, 2020, doi:doi = https://doi.org/10.1016/j.jasrep.2020.102440.

[4] ICOMOS. Principles for the analysis, conservation and structural restoration of architectural heritage. In Rap. tech., 14th General Assembly of ICOMOS, 2003.

[5] Alemdar Bayraktar, Temel Türker, Barış Sevım, Ahmet Can Altunişik, and Faruk Yildirim. Modal parameter identification of hagia sophia bell-tower via ambient vibration test. Journal of Nondestructive Evaluation, 28(1):37-47, 2009, doi:https://doi.org/10.1007/s10921-009-0045-9.

[6] Clotaire Michel. Vulnérabilité Sismique de l'échelle du bâtiment à celle de la ville-Apport des techniques expérimentales in situ-Application à Grenoble. PhD thesis, Université Joseph-Fourier-Grenoble I, 2007.

[7] Rodrigo Sarlo, Pablo A Tarazaga, and Mary E Kasarda. High resolution operational modal analysis on a fivestory smart building under wind and human induced excitation. Engineering Structures, 176:279-292, 2018, doi:https://doi.org/10.1016/j.engstruct.2018.08.060.

[8] Oriol Caselles, Guillermo Martínez, Jaume Clapes, Pere Roca, and Maria de la Vega Pérez-Gracia. Application of particle motion technique to structural modal identification of heritage buildings. International Journal of Architectural Heritage, 9(3):310-323, 2015, doi:https://doi.org/10.1080/15583058.2013.784824.

[9] A De Stefano and $R$ Ceravolo. Assessing the health state of ancient structures: the role of vibrational tests. Journal of intelligent material systems and structures, 18(8):793-807, 2007, doi:https://doi.org/10.1177/1045389X06074610.

[10] Claire Limoge-Schraen, Cedric Giry, Cedric Desprez, and Frédéric Ragueneau. Toward a large-scale seismic assessment method for heritage building: vulnerability of masonry baroque churches. European Journal of Environmental and Civil Engineering, 20(6):680-710, 2016, doi:https://doi.org/10.1080/19648189.2015.1061459.

[11] Emre Ercan. Assessing the impact of retrofitting on structural safety in historical buildings via ambient vibration tests. Construction and Building Materials, 164:337-349, 2018, doi:https://doi.org/10.1016/j.conbuildmat.2017.12.154.

[12] Dora Foti, Mariella Diaferio, Nicola Ivan Giannoccaro, and Michele Mongelli. Ambient vibration testing, dynamic identification and model updating of a historic tower. NDT $\mathscr{G}$ e International, 47:88-95, 2012, doi:https://doi.org/10.1016/j.ndteint.2011.11.009.

[13] Paulo B Lourenço, Konrad J Krakowiak, FM Fernandes, and Luís F Ramos. Failure analysis of monastery of jerónimos, lisbon: How to learn from sophisticated numerical models. Engineering Failure Analysis, 14(2):280300, 2007, doi:https://doi.org/10.1016/j.engfailanal.2006.02.002.

[14] Carmelo Gentile, Antonello Ruccolo, and Antonella Saisi. Continuous dynamic monitoring to enhance the knowledge of a historic bell-tower. International Journal of Architectural Heritage, 13(7):992-1004, 2019, doi:https://doi.org/10.1080/15583058.2019.1605552.

[15] Carmelo Gentile, Antonella Saisi, and Alessandro Cabboi. Structural identification of a masonry tower based on operational modal analysis. International Journal of Architectural Heritage, 9(2):98-110, 2015, doi:https://doi.org/10.1080/15583058.2014.951792. 
[16] Luis Javier Sánchez-Aparicio, Belén Riveiro, Diego Gonzalez-Aguilera, and Luís F Ramos. The combination of geomatic approaches and operational modal analysis to improve calibration of finite element models: A case of study in saint torcato church (guimarães, portugal). Construction and Building Materials, 70:118-129, 2014, doi:https://doi.org/10.1016/j.conbuildmat.2014.07.106.

[17] Jorge Manuel Vieira Borges Lourenço Rodrigues et al. Identificação modal estocástica: métodos de análise e aplicações em estruturas de engenharia civil. 2005.

[18] Luis F Ramos, Leandro Marques, Paulo B Lourenço, Guido De Roeck, A Campos-Costa, and João Roque. Monitoring historical masonry structures with operational modal analysis: two case studies. Mechanical systems and signal processing, 24(5):1291-1305, 2010, doi:https://doi.org/10.1016/j.ymssp.2010.01.011.

[19] Arnaud Montabert. Characterizing ground motion of historical earthquakes. Study of Sant'Agata del Mugello combining building archaeology, earthquake engineering and seismology. PhD thesis, Paris Sciences et Lettres University, 2021.

[20] Wilson Torres, José Luis Almazán, Cristián Sandoval, and Rubén Boroschek. Operational modal analysis and fe model updating of the metropolitan cathedral of santiago, chile. Engineering Structures, 143:169-188, 2017, doi:https://doi.org/10.1016/j.engstruct.2017.04.008.

[21] Ilaria Capanna, Riccardo Cirella, Angelo Aloisio, Rocco Alaggio, Franco Di Fabio, and Massimo Fragiacomo. Operational modal analysis, model update and fragility curves estimation, through truncated incremental dynamic analysis, of a masonry belfry. Buildings, 11(3):120, 2021, doi:https://doi.org/10.3390/buildings11030120.

[22] Agnieszka Tomaszewska. Influence of statistical errors on damage detection based on structural flexibility and mode shape curvature. Computers \&5 structures, 88(3-4):154-164, 2010, doi:https://doi.org/10.1016/j.compstruc.2009.08.017.

[23] Angelo Aloisio, Elena Antonacci, Massimo Fragiacomo, and Rocco Alaggio. The recorded seismic response of the santa maria di collemaggio basilica to low-intensity earthquakes. International Journal of Architectural Heritage, pages 1-19, 2020, doi:https://doi.org/10.1080/15583058.2020.1802533.

[24] B Peeters, G Sforza, L Sbaraglia, and F Germano. Efficient operational modal testing and analysis for design verification and restoration baseline assessment: Italian case studies. Proceedings of the Experimental Vibration Analysis for Civil Engineering Structures (EVACES), pages 3-5, 2011.

[25] P Bonato, R Ceravolo, A De Stefano, and F Molinari. Application of the time-frequency estimators method to the identification of masonry buildings. Mechanical Systems and Signal Processing, 14:91-109, 2000, doi:https://doi.org/10.1006/mssp.1999.1273.

[26] Emanuele Lorenzo, Francesca Canessa, Giuseppe Chellini, Anna De Falco, Carlo Resta, E Savelli, and G Sevieri. Modal identification of the san francesco church in pisa, italy. In EURODYN 2020-XI International Conference on Structural Dynamics, volume 1, pages 2386-2399. EASD European Association for Structural Dynamics, 2020 .

[27] T Yamamoto and T Maeda. Earthquake safety assessment of a tall brick chimney in tokoname based on the micro-tremor measurement. In 14th World Conference on Earthquake Engineering, 2008.

[28] Salvatore Russo, Domenico Liberatore, and Luigi Sorrentino. Combined nd techniques for structural assessment: the case of historic nepali constructions after the 2015 gorkha earthquake. In Multidisciplinary Digital Publishing Institute Proceedings, volume 2, page 421, 2018.

[29] Angelo Salvatore Carone, Dora Foti, Nicola Ivan Giannoccaro, and Riccardo Nobile. Non-destructive characterization and dynamic identification of an historical bell tower. In Proceedings in the 4th international conference on integrity, reliability and failure, Funchal, Portugal, pages 1-16, 2013.

[30] M Diaferio, D Foti, and NI Giannoccaro. Modal parameters identification on environmental tests of an ancient tower and validation of its fe model. International Journal of Mechanics, 10:80-89, 2016. 
[31] Carmelo Gentile and A Saisi. Ambient vibration testing of historic masonry towers for structural identification and damage assessment. Construction and building materials, 21(6):1311-1321, 2007, doi:https://doi.org/10.1016/j.conbuildmat.2006.01.007.

[32] Filippo Casarin and Claudio Modena. Seismic assessment of complex historical buildings: application to reggio emilia cathedral, italy. International Journal of Architectural Heritage, 2(3):304-327, 2008, doi:https://doi.org/10.1080/15583050802063659.

[33] Valter Lopes, João Miranda Guedes, Esmeralda Paupério, António Arêde, and Aníbal Costa. Ambient vibration testing and seismic analysis of a masonry chimney. Journal of Building Appraisal, 5(2):101-121, 2009, doi:https://doi.org/10.1057/jba.2009.24.

[34] Riccardo Mario Azzara, Maria Girardi, Valerio Iafolla, David M Lucchesi, Cristina Padovani, and Daniele Pellegrini. Ambient vibrations of age-old masonry towers: Results of long-term dynamic monitoring in the historic centre of lucca. International Journal of Architectural Heritage, 15(1):5-21, 2021, doi:https://doi.org/10.1080/15583058.2019.1695155.

[35] Giacomo Buffarini, Paolo Clemente, Sandro Serafini, Alessandro De Stefano, Roberta Olivieri, and Antonello Salvatori. Experimental dynamic analysis and seismic rehabilitation of palazzo margherita in l'aquila. Speciale. Natural Risks and Protection, pages 63-70.

[36] F Lorenzoni, MR Valluzzi, M Salvalaggio, A Minello, and C Modena. Operational modal analysis for the characterization of ancient water towers in pompeii. Procedia engineering, 199:3374-3379, 2017, doi:https://doi.org/10.1016/j.proeng.2017.09.446.

[37] Bijaya Jaishi, Wei-Xin Ren, Zhou-Hong Zong, and Prem Nath Maskey. Dynamic and seismic performance of old multi-tiered temples in nepal. Engineering Structures, 25(14):1827-1839, 2003, doi:https://doi.org/10.1016/j.engstruct.2003.08.006.

[38] Rosario Ceravolo, Giuseppe Pistone, Luca Zanotti Fragonara, Stefano Massetto, and Giuseppe Abbiati. Vibration-based monitoring and diagnosis of cultural heritage: a methodological discussion in three examples. International Journal of Architectural Heritage, 10(4):375-395, 2016, doi:https://doi.org/10.1080/15583058.2013.850554.

[39] T Pelella, G Mannara, E Cosenza, I Iervolino, and L Lecce. Structural dynamic investigations on the bell tower from the s. lucia's church-serra s. quirico, ancona. In Proceedings of the 7th International Seminar on Seismic Isolation, Passive Energy Dissipation and Active Control of Vibrations of Structures, pages 2-5. Italy Assisi, 2001.

[40] C Casapulla, F Ceroni, C Rainieri, LU Argiento, P Arcamone, and G Fabbrocino. Structural assessment of santa maria maddalena church in ischia island (italy) by experimental modal analysis under operational conditions. In Proceedings of the VII ECCOMAS Thematic Conference of Compytational Methods in Structural Dynamics and Earthquake Engineering (COMPDYN 2019), Crete, Greece, pages 24-26, 2019.

[41] AG El-Attar, AM Saleh, and AH Zaghw. Conservation of a slender historical mamluk-style minaret by passive control techniques. Structural Control and Health Monitoring: The Official Journal of the International Association for Structural Control and Monitoring and of the European Association for the Control of Structures, 12(2):157-177, 2005, doi:https://doi.org/10.1002/stc.54.

[42] Antonio Formisano, Gianmaria Di Lorenzo, Lidija Krstevska, and Raffaele Landolfo. Fem model calibration of experimental environmental vibration tests on two churches hit by l'aquila earthquake. International Journal of Architectural Heritage, 15(1):113-131, 2021, doi:https://doi.org/10.1080/15583058.2020.1719233.

[43] Giovanni Bongiovanni, Paolo Clemente, and Giacomo Buffarini. Analysis of the seismic response of a damaged masonry bell tower. In 12th World Conference on Earthquake Engineering, Auckland, New Zealand, volume 30, 2000 . 
[44] Riccardo Mario Azzara, Maria Girardi, Cristina Padovani, and Daniele Pellegrini. Experimental and numerical investigations on the seismic behaviour of the san frediano bell tower in lucca. Annals of Geophysics, 2019, doi:http://hdl.handle.net/2122/13412.

[45] Francesca Ceroni, Marisa Pecce, Simona Voto, and Gaetano Manfredi. Historical, architectural, and structural assessment of the bell tower of santa maria del carmine. International Journal of Architectural Heritage, 3(3):169-194, 2009.

[46] Giacomo Zonno, Rafael Aguilar, Rubén Boroschek, and Paulo B Lourenço. Environmental and ambient vibration monitoring of historical adobe buildings: applications in emblematic andean churches. International Journal of Architectural Heritage, pages 1-17, 2019, doi:https://doi.org/10.1080/15583058.2019.1653402.

[47] Arūnas Jaras, Romualdas Kliukas, and Rimantas Kačianauskas. The dynamic loading of vilnius archcathedral belfry-investigation and analysis. 2010.

[48] Annamaria Pau and Fabrizio Vestroni. Dynamic characterization of ancient masonry structures. Advances in Vibration Analysis Research, pages 213-230, 2011.

[49] Angelo Aloisio, Alessandro Di Pasquale, Rocco Alaggio, and Massimo Fragiacomo. Assessment of seismic retrofitting interventions of a masonry palace using operational modal analysis. International Journal of Architectural Heritage, pages 1-13, 2020, doi:https://doi.org/10.1080/15583058.2020.1836531.

[50] CS Oliveira, E Çaktı, D Stengel, and M Branco. Minaret behavior under earthquake loading: The case of historical istanbul. Earthquake Engineering \& Structural Dynamics, 41(1):19-39, 2012, doi:https://doi.org/10.1002/eqe.1115.

[51] Francesco Eusani and Francesco Benedettini. Modal and structural identification of a masonry chimney. In Proceedings of 19th Congress of Italian Association for Theoretical and Applied Mechanics, Ancona, Italy, pages 14-17, 2009.

[52] Donato Abruzzese, Lorenzo Miccoli, Alessandro Vari, Massimiliano Ferraioli, Alberto Mandara, and Salvatore Froncillo. Dynamic investigations on medieval masonry towers: vibration measurement and structural identification. In Proceedings of the international conference on protection of historical buildings. Rome, pages 807-813, 2009.

[53] Andrés Burgos Braga, Paulo B Lourenco, and Nuno Mendes. Seismic assessment of the medieval armenian church in famagusta, cyprus. 2019.

[54] G Standoli, E Giordano, G Milani, and F Clementi. Model updating of historical belfries based on oma identification techniques. International Journal of Architectural Heritage, 15(1):132-156, 2021, doi:https://doi.org/10.1080/15583058.2020.1723735.

[55] ML Pecorelli, R Ceravolo, G De Lucia, and R Epicoco. A vibration-based health monitoring program for a large and seismically vulnerable masonry dome. In Journal of Physics: Conference Series, volume 842, page 012009. IOP Publishing, 2017.

[56] Salvador Ivorra, Francisco J Pallarés, Jose M Adam, and Roberto Tomás. An evaluation of the incidence of soil subsidence on the dynamic behaviour of a gothic bell tower. Engineering Structures, 32(8):2318-2325, 2010, doi:https://doi.org/10.1016/j.engstruct.2010.04.007.

[57] Abraham R Sánchez, Roberto Meli, and Marcos M Chávez. Structural monitoring of the mexico city cathedral (1990-2014). International Journal of Architectural Heritage, 10(2-3):254-268, 2016, doi:https://doi.org/10.1080/15583058.2015.1113332.

[58] MA Zaki, AF Hassan, SA Mourad, and AM Osman. Evaluation of the structural integrity of historical stone minarets. In Proceedings of the 14th World Conference on Earthquake Engineering, pages 12-17, 2008. 
[59] Manjip Shakya, Humberto Varum, Romeu Vicente, and Aníbal Costa. Seismic sensitivity analysis of the common structural components of nepalese pagoda temples. Bulletin of earthquake engineering, 12(4):16791703, 2014, doi:https://doi.org/10.1007/s10518-013-9569-6.

[60] S Casciati and R Al-Saleh. Dynamic behavior of a masonry civic belfry under operational conditions. Acta mechanica, 215(1):211-224, 2010, doi:https://doi.org/10.1007/s00707-010-0343-4.

[61] Angelo D’Ambrisi, Valentina Mariani, and Marco Mezzi. Seismic assessment of a historical masonry tower with nonlinear static and dynamic analyses tuned on ambient vibration tests. Engineering Structures, 36:210-219, 2012, doi:https://doi.org/10.1016/j.engstruct.2011.12.009.

[62] N Nisticò, S Gambarelli, A Fascetti, and G Quaranta. Experimental dynamic testing and numerical modeling of historical belfry. International Journal of Architectural Heritage, 10(4):476-485, 2016, doi:https://doi.org/10.1080/15583058.2014.1003622.

[63] Gianni Bartoli, Michele Betti, and Saverio Giordano. In situ static and dynamic investigations on the "torre grossa" masonry tower. Engineering Structures, 52:718-733, 2013, doi:https://doi.org/10.1016/j.engstruct.2013.01.030.

[64] A Cigada, L Corradi Dell'Acqua, B Mörlin Visconti Castiglione, M Scaccabarozzi, M Vanali, and E Zappa. Structural health monitoring of an historical building: The main spire of the duomo di milano. International Journal of Architectural Heritage, 11(4):501-518, 2017, doi:https://doi.org/10.1080/15583058.2016.1263691.

[65] Paul H Kohan, Liz G Nallim, and Susana B Gea. Dynamic characterization of beam type structures: Analytical, numerical and experimental applications. Applied acoustics, 72(12):975-981, 2011, doi:https://doi.org/10.1016/j.apacoust.2011.06.007.

[66] G Russo, O Bergamo, L Damiani, and D Lugato. Experimental analysis of the "saint andrea" masonry bell tower in venice. a new method for the determination of "tower global young's modulus e". Engineering structures, 32(2):353-360, 2010, doi:https://doi.org/10.1016/j.engstruct.2009.08.002.

[67] T Aoki and D Sabia. Theoretical and experimental analysis of brick chimneys, tokoname, japan. Proceedings of WCCM VI in conjunction with APCOM'04, Computational Mechanics, 2004.

[68] Dora Foti, Salvador Ivorra, Maria Francesca Sabbà, et al. Dynamic investigation of an ancient masonry bell tower with operational modal analysis: A non-destructive experimental technique to obtain the dynamic characteristics of a structure. 2012.

[69] Vincenzo Sepe, Elena Speranza, and Alberto Viskovic. A method for large-scale vulnerability assessment of historic towers. Structural Control and Health Monitoring: The Official Journal of the International Association for Structural Control and Monitoring and of the European Association for the Control of Structures, 15(3):389415, 2008, doi:https://doi.org/10.1002/stc.243.

[70] G Camata, L Cifelli, E Spacone, J Conte, and P Torrese. Safety analysis of the bell tower of s. maria maggiore cathedral in guardiagrele (italy). In Proceedings of the 14 th World Conference on Earthquake Engineering, pages $12-17,2008$.

[71] Salvador Ivorra and Francisco J Pallarés. Dynamic investigations on a masonry bell tower. Engineering structures, 28(5):660-667, 2006, doi:https://doi.org/10.1016/j.engstruct.2005.09.019.

[72] Marco Bonini, Giacomo Corti, Dario Delle Donne, Federico Sani, Luigi Piccardi, Gianfranco Vannucci, Riccardo Genco, Luca Martelli, and Maurizio Ripepe. Seismic sources and stress transfer interaction among axial normal faults and external thrust fronts in the northern apennines (italy): A working hypothesis based on the 1916-1920 time-space cluster of earthquakes. Tectonophysics, 680:67-89, 2016, doi:https://doi.org/10.1016/j.tecto.2016.04.045.

[73] Andrea Rovida, Mario Locati, Romano Daniele Camassi, Barbara Lolli, and Paolo Gasperini. Catalogo parametrico dei terremoti italiani (cpti15), 2016. 
[74] Marco Bonini, Giacomo Corti, Dario Delle Donne, Federico Sani, Luigi Piccardi, Gianfranco Vannucci, Riccardo Genco, Luca Martelli, and Maurizio Ripepe. Seismic sources and stress transfer interaction among axial normal faults and external thrust fronts in the northern apennines (italy): A working hypothesis based on the 1916-1920 time-space cluster of earthquakes. Tectonophysics, 680:67-89, June 2016, doi:10.1016/j.tecto.2016.04.045.

[75] Andrea Arrighetti. Constructive and seismic history of the sant'agata del mugello parish church. In Palmero Iglesias LM, editor, reuso 2015. III congreso internacional sobre documentacion, conservacion y reutilizacion del patrimonio arquitectonico y paisajistico, pages 64-70, Valencia - ESP, 2015 2015. Editorial Universitat Politècnica de València. Contributo in Atti di convegno.

[76] Rune Brincker, Carlos E Ventura, and Palle Andersen. Damping estimation by frequency domain decomposition. In Proceedings of IMAC 19: A Conference on Structural Dynamics: februar 5-8, 2001, Hyatt Orlando, Kissimmee, Florida, 2001, pages 698-703. Society for Experimental Mechanics, 2001.

[77] David J Ewins. Modal testing: theory, practice and application. John Wiley \& Sons, 2009.

[78] AC Aktinson. Bendat, js, and piersol, ag (1986). random data: Analysis and measurement procedures. john wiley \& sons, new york, ny xiii +566 pp. s49. 95. berry, da, and fristedt, b.(1985). bandit prob. Statistical Science, 2(1):101-103, 1987.

[79] Rune Brincker, Lingmi Zhang, and P Andersen. Modal identification from ambient responses using frequency domain decomposition. In Proc. of the 18*'International Modal Analysis Conference (IMAC), San Antonio, Texas, 2000.

[80] Peter Welch. The use of fast fourier transform for the estimation of power spectra: a method based on time averaging over short, modified periodograms. IEEE Transactions on audio and electroacoustics, 15(2):70-73, 1967, doi:10.1109/TAU.1967.1161901.

[81] Jorge Rodrigues and Rune Brincker. Application of the random decrement technique in operational modal analysis. In Proceedings of the 1st International Operational Modal Analysis Conference, April 26-27, 2005, Copenhagen, Denmark, pages 191-200. Aalborg Universitet, 2005.

[82] Seon Ho Song and Myung Jo Jhung. Experimental modal analysis on the core support barrel of reactor internals using a scale model. 13(8):585-594, August 1999, doi:10.1007/bf03184552.

[83] Claire Limoge. Méthode de diagnostic à grande échelle de la vulnérabilité sismique des Monuments Historiques: Chapelles et églises baroques des hautes vallées de Savoie. PhD thesis, Université Paris-Saclay (ComUE), 2016.

[84] David L Hunt. Application of an enhanced coordinate modal assurance criterion. In 10th International modal analysis conference, volume 1, pages 66-71, 1992.

[85] Ting-Hua Yi, Hong-Nan Li, and Ming Gu. Optimal sensor placement for structural health monitoring based on multiple optimization strategies. The Structural Design of Tall and Special Buildings, 20(7):881-900, 2011, doi:https://doi.org/10.1002/tal.712. 